




\section{Ayuntamiento y plaza de la Constitución de Almería. Ampliación, reforma, rehabilitación}

José Ramón Sierra Delgado, arquitecto

\section{Resumen}

La antigua Plaza Vieja, centro de la Almería antigua, reúne un grupo heterogéneo de edificios donde se encuentran ubicadas desde 1656 las casas del Concejo de la ciudad. El resto son viviendas particulares y el convento de Santa Clara. A mediados del s. XIX el conjunto recibió un frente continuo con intención de Plaza Mayor. Intervenciones diversas habian producido un conjunto disfuncional, mal distribuido y dificil de mantener.

La intervención ha pretendido fines funcionales y otros de identidad formal y respeto patrimonial con las exigencias actuales y la herencia cultural de Almería y entorno, implicando valores paisajisticos en relación con la Alcazaba y con el cerro de San Cristóbal.

Las más significativas operaciones en la fase 1 han sido:

- demolición de las edificaciones alineadas a calle Pósito y a calle Juez;

- rehabilitación de la galería a la Plaza, recuperándose el carácter unitario interior, y su capacidad distributiva, de paseo y descanso; - edificaciones de nueva planta que sustituyen a las zonas demolidas en dos sectores diferenciados. Uno es el edificio longitudinal de calle Pósito y otro el del nuevo salón de plenos; - configuración de la nueva cubierta como zona de recepción y encuentros desde la que disfrutar vistas magníficas de la ciudad y su entorno.

\section{Palabras clave}

Almeria / Ayuntamiento / Casas consistoriales / Edificios históricos / Edificios públicos administrativos / Intervención / Patrimonio inmueble / Plazas / Rehabilitación 


\section{RESEÑA HISTÓRICA}

La antigua Plaza Vieja, hoy de la Constitución, de Almería, centro urbano de la ciudad antigua y actualmente núcleo de una extensa zona degradada, concentra un grupo heterogéneo de edificios en cuyo conjunto se encuentran ubicadas desde 1656 las casas del Concejo de la ciudad, dándose así refrendo oficial a lo que desde antes había venido usándose como centro comercial y urbano de Almeria desde que el terremoto de 1522 produjo el abandono del barrio de la Almedina, lugar del primitivo corazón islámico. El resto de los frentes a dicha plaza estaba ocupado por viviendas de particulares, excepto el lado de oriente, formado por edificaciones del Convento de Santa Clara. A mediados del siglo XIX todo el conjunto recibirá un nuevo frente continuo con intención de Plaza Mayor, en tardio seguimiento de tantas otras similares operaciones en ciudades españolas, aunque de muy modesto aparato figurativo, formalizado por una crujía de tres plantas con arcos carpaneles en la inferior y balcones en las superiores. Todo ello extendido como un velo superpuesto al conjunto desigual de las antiguas edificaciones domésticas y municipales, que avanzarian ocupando su parte correspondiente de estas nuevas galerías. $Y_{1}$ por tanto, asimilando espacios de muy distinta espacialidad, dimensiones, alturas y sistemas constructivos a los propios y diversos de cada una de las antiguas edificaciones afectadas. Quizá incluso incluyendo alguna operación de seccionado sobre una alineación seguramente irregular.

La propia historia de las Casas Consistoriales ha sido un cúmulo de intervenciones dispares que había producido un conjunto disfuncional de recintos poco adecuados y mal distribuidos. El Ayuntamiento fue poco a poco tratando de resolver las serias carencias de espacios incorporando otras casas de la plaza a través de diversas operaciones proyectuales (colmataciones de la crujía de fachada, obras de nueva planta, sustituciones, etcétera) que no consiguieron solucionar los problemas funcionales de un aglomerado por otro lado difícil de atender y mantener y en continuo crecimiento. Habiéndose llegado a un punto extremo de insuficiencia dimensional, inadecuación zonal e ineficacia funcional, en momentos de máximo crecimiento y especificidad de usos y servicios, con el consiguiente desperdigamiento desordenado de partes por distintos edificios de la ciudad.

Ante tal estado de cosas, aparecían dos tipos de solución, ambos característicos de situaciones parecidas, por lo demás muy frecuentes en el devenir de la ciudad histórica:

a) El abandono del caótico conjunto, reubicando el Ayuntamiento en una nueva sede construida ex profeso en alguna de las nuevas zonas de expansión de la ciudad moderna.

b) Afrontar una ampliación y rehabilitación integral del mismo, incorporando alguna otra edificación anexa, aun aceptando la imposibilidad de ocupar la totalidad del perimetro de la plaza que, incluyendo Santa Clara, hubiese sido un ideal remoto.

\section{La propuesta surgía de una manera particular de entender la arquitectura: considerarla como servicio, como conjunto de escuetas y económicas transformaciones tendentes a la resolución de los problemas, inadecuaciones e insuficiencias identificados}

La solución a, abandono y obra nueva, de seguro atractivo desde el punto de vista de una política de resultados brillantes y corto plazo, compatible con los tiempos reducidos de mandatos municipales, implicaba también, sobre todo, el abandono de todo un barrio de importantísima tradición urbana, base y camino de la Alcazaba, límite natural del cerro de San Cristóbal y de la Hoya y cuya rehabilitación seguiria siendo de urgente acometida.

La solución b, ampliación y rehabilitación, significaba apostar por el lugar histórico de las Casas Consistoriales y la confianza en el papel que éstas podian jugar como motor para la recuperación de una zona urbana de tanta significación antigua y futura. Aun contando con la dificultad añadida aportada por los restos edilicios del Ayuntamiento viejo, de los que no sería posible prescindir, sin aportar casi calidad arquitectónica alguna.

Ambas posiciones están bien representadas en otros ámbitos andaluces y muy especialmente en el ya largo y complicado proceso de residenciar en la nueva capital andaluza, Sevilla, las sedes de las instituciones de la capitalidad. Que comenzó primando, en general, rehabilitaciones de edificios antiguos imbricados en el viejo tejido urbano, seguramente pensando en la capacidad regeneradora ambiental, aunque, desgraciada e incomprensiblemente, eligiendo edificios de supuesta raigambre "nobiliaria" y estilistica y abandonando la arquitectura popular, verdadero componente de dicho tejido. Para sucumbir más adelante a la fascinación por una arquitectura de nueva planta y periférica, perfectamente acorde con los más vulgares estigmas de la arquitectura contemporánea corporativa y comercial. El excepcionalmente grande recinto urbano amurallado se habia caracterizado, además, por el uso permanente de la reforma continua y sucesiva como forma primordial de construcción, evolución y transformación urbanística. Esa tradición se rompe- 
TIPOS DE INTERVENCIONES

1-9 EDIFICIOS A INTERVENR

A-D EDIFICIOS INTERVENIDOS

YA DEMOLIDAS

$\$$ DEMOLICIONES

\#IIIII REHABLITACIONES

El NUEVA PLANTA

VIIIIIIA FASE 1

UIIIIJ FASE 2
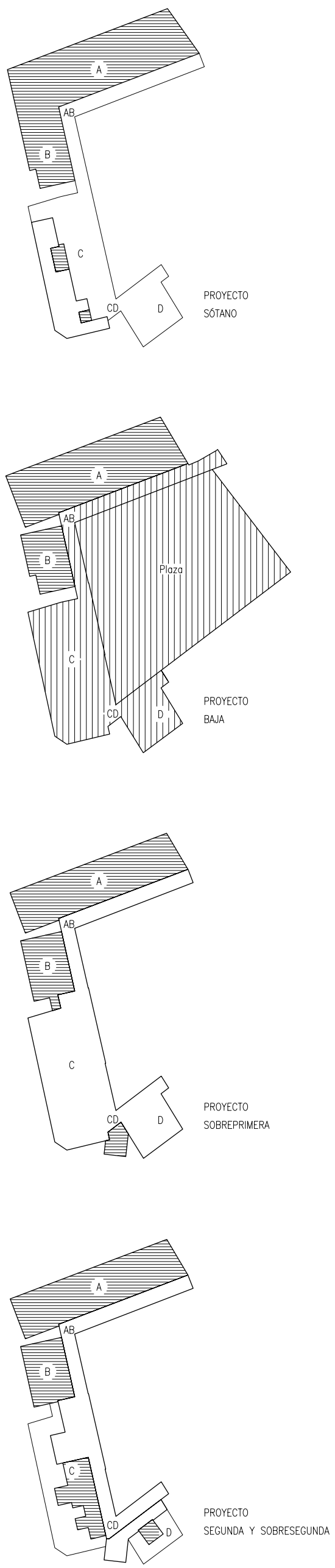

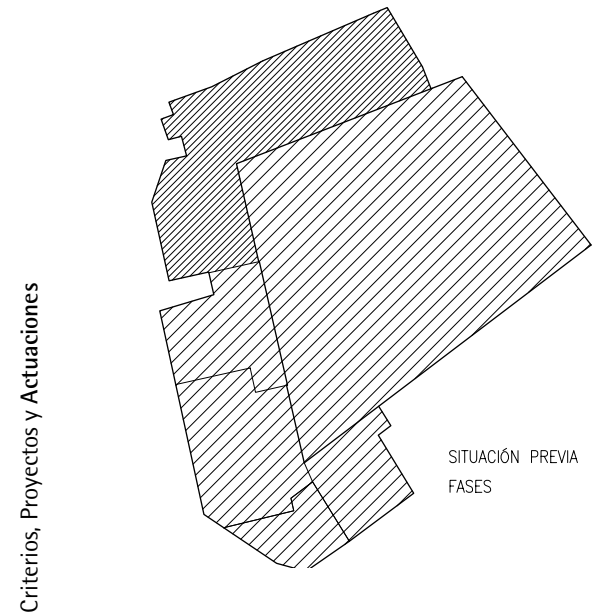




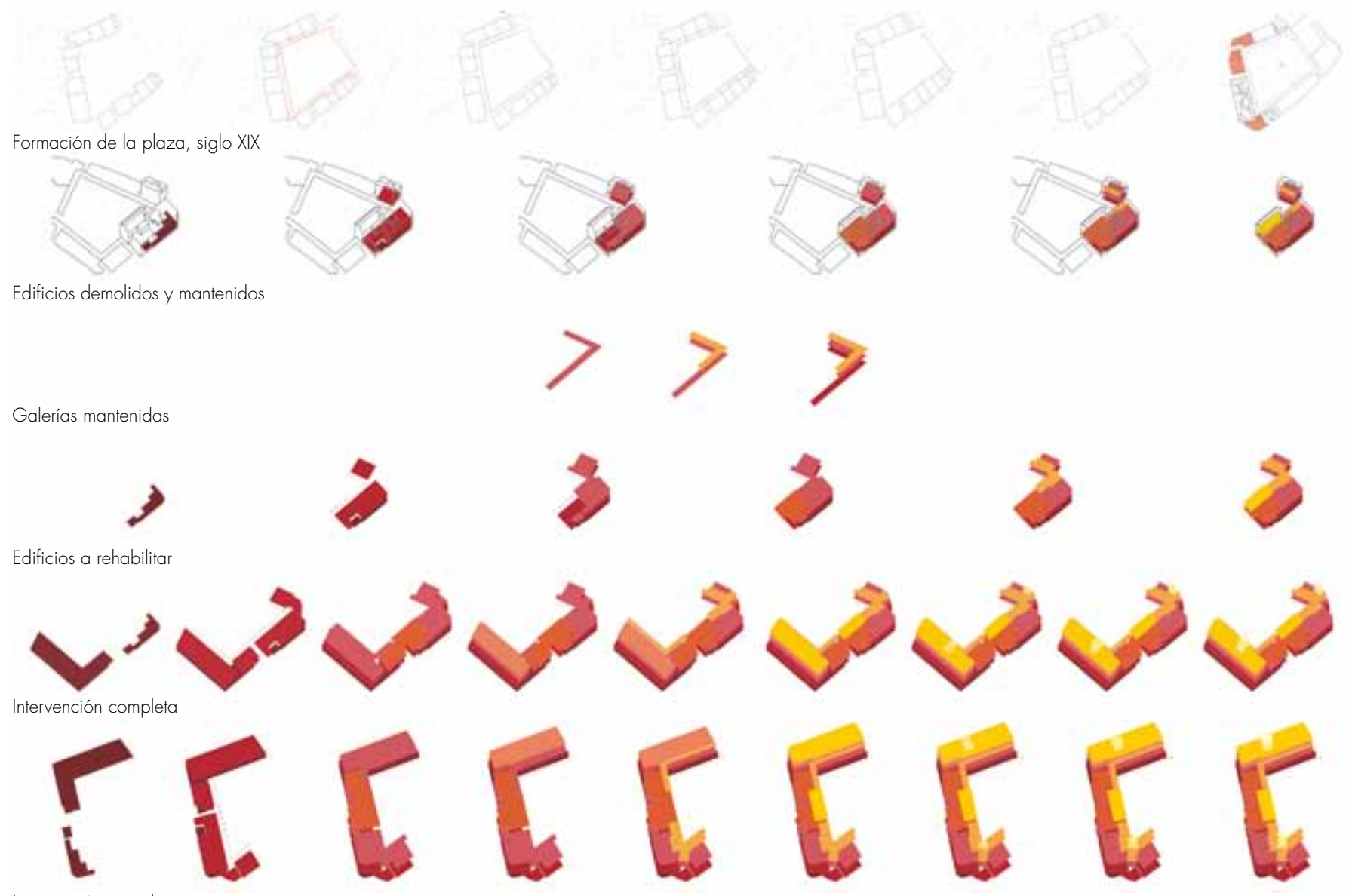

Intervención completa
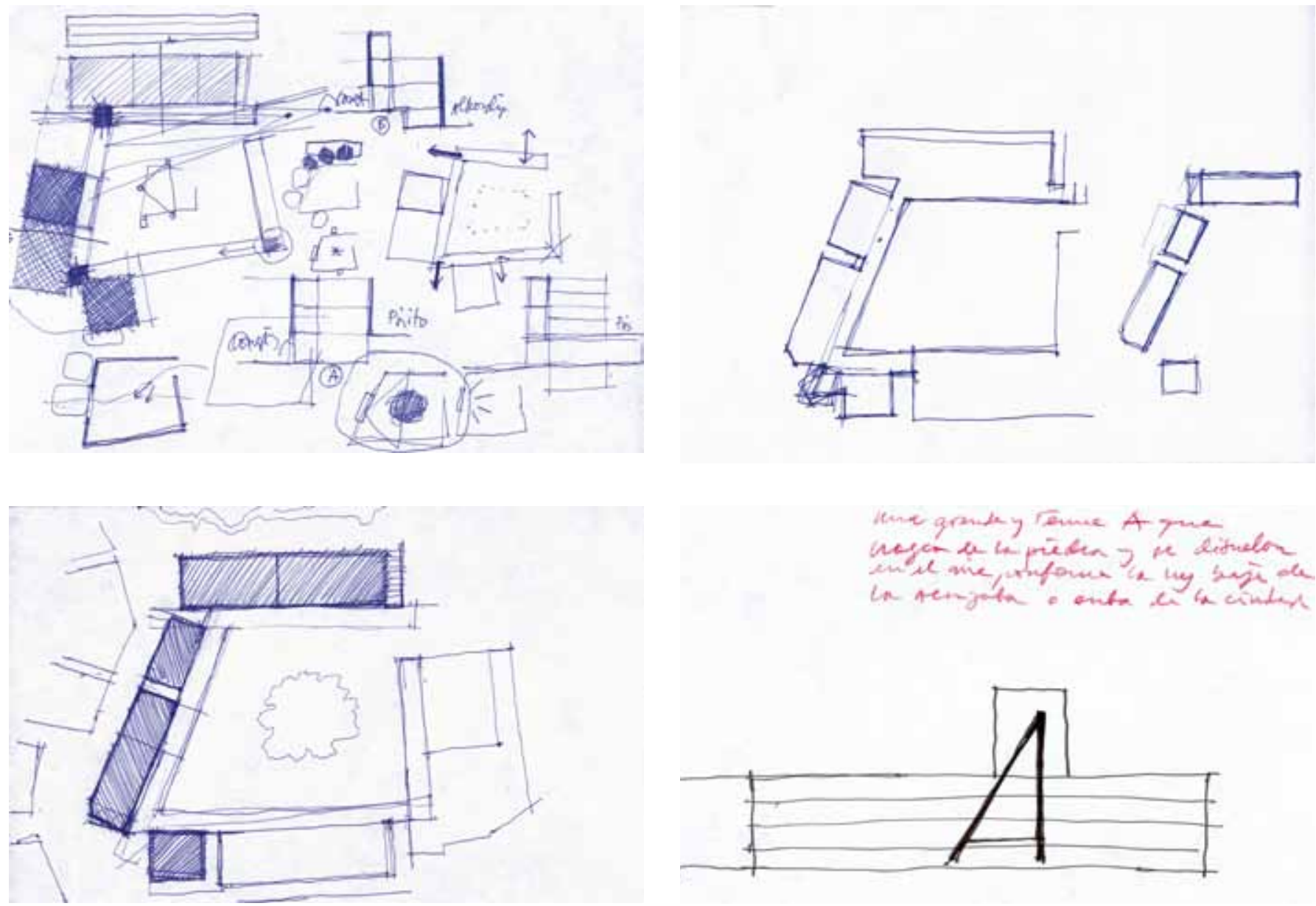


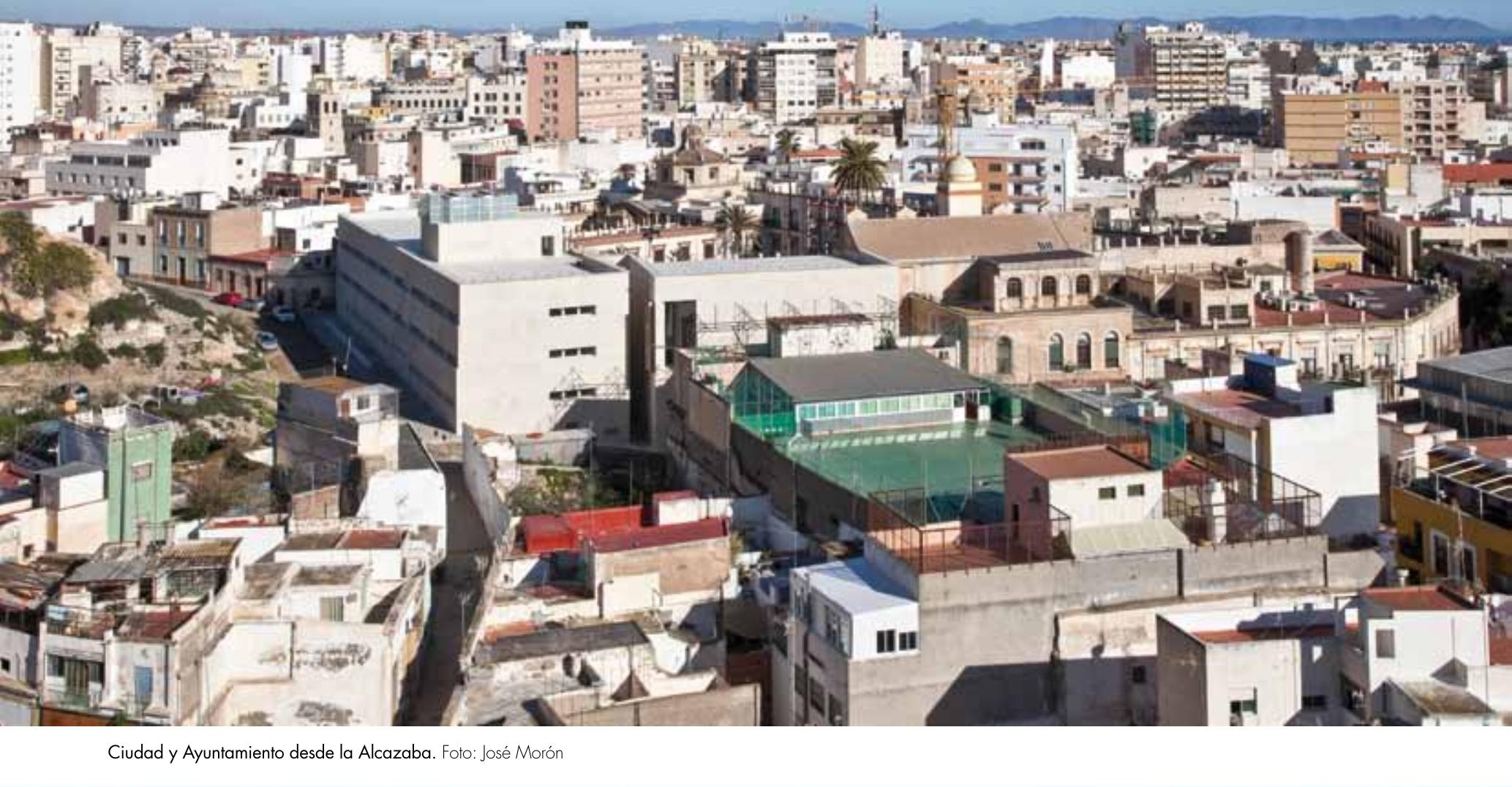

Ciudad y Ayuntamiento desde la Alcazaba. Foto: José Morón

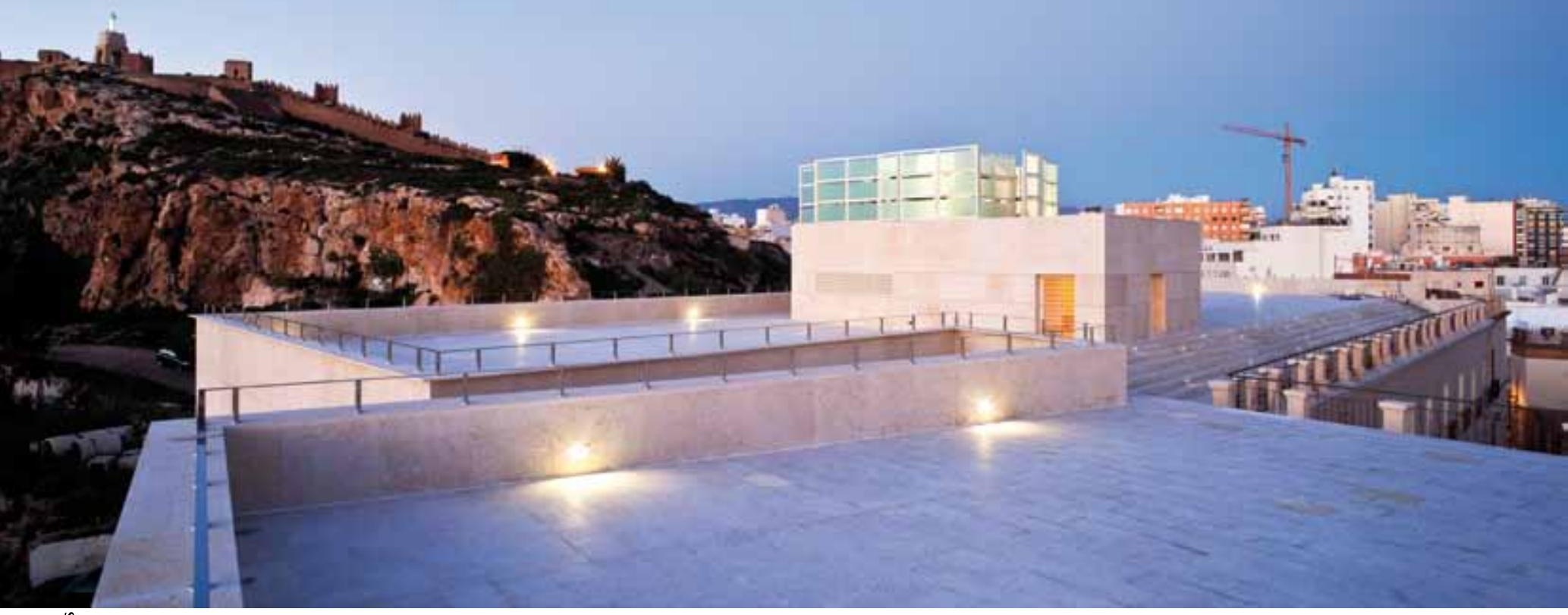



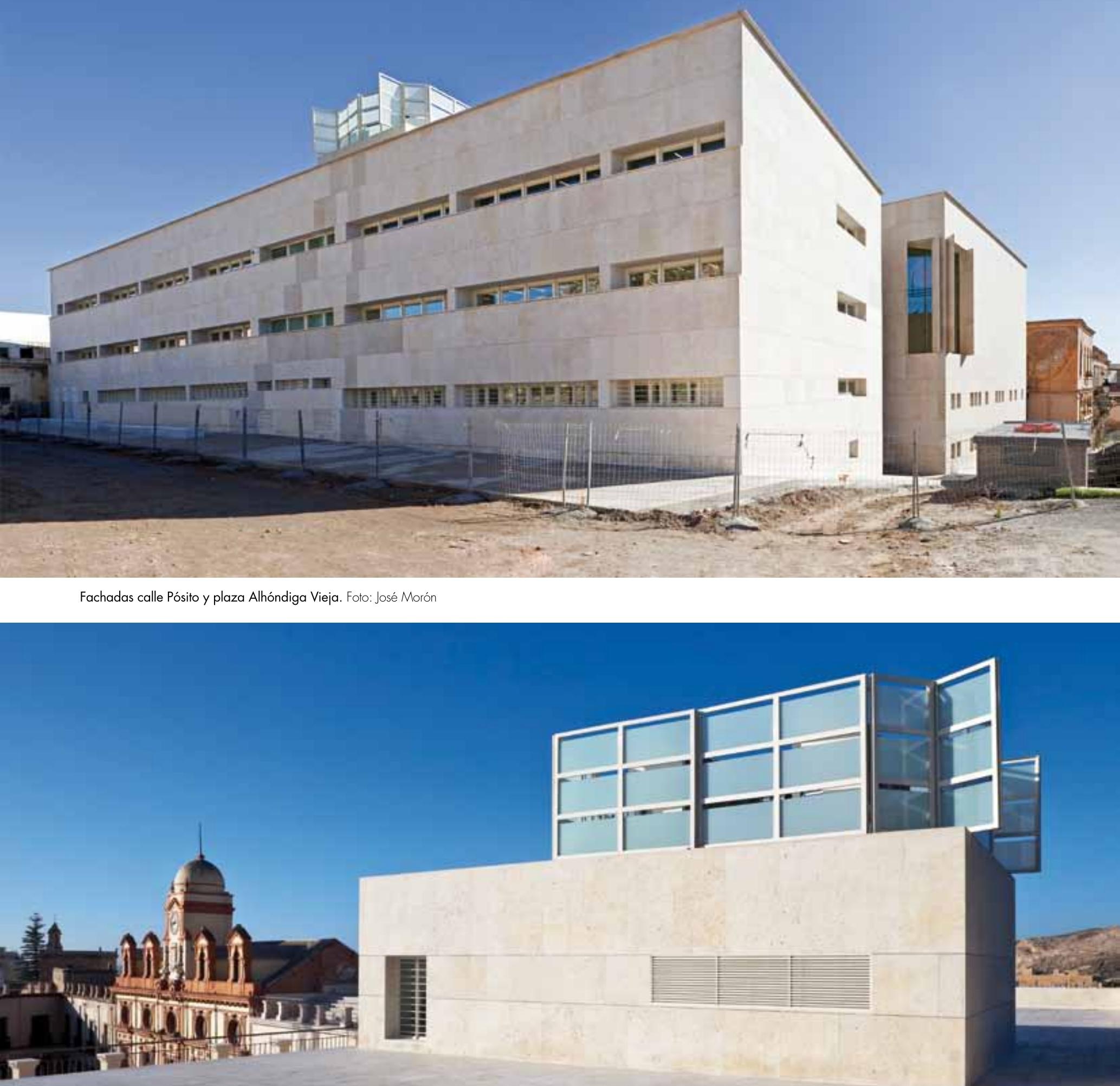

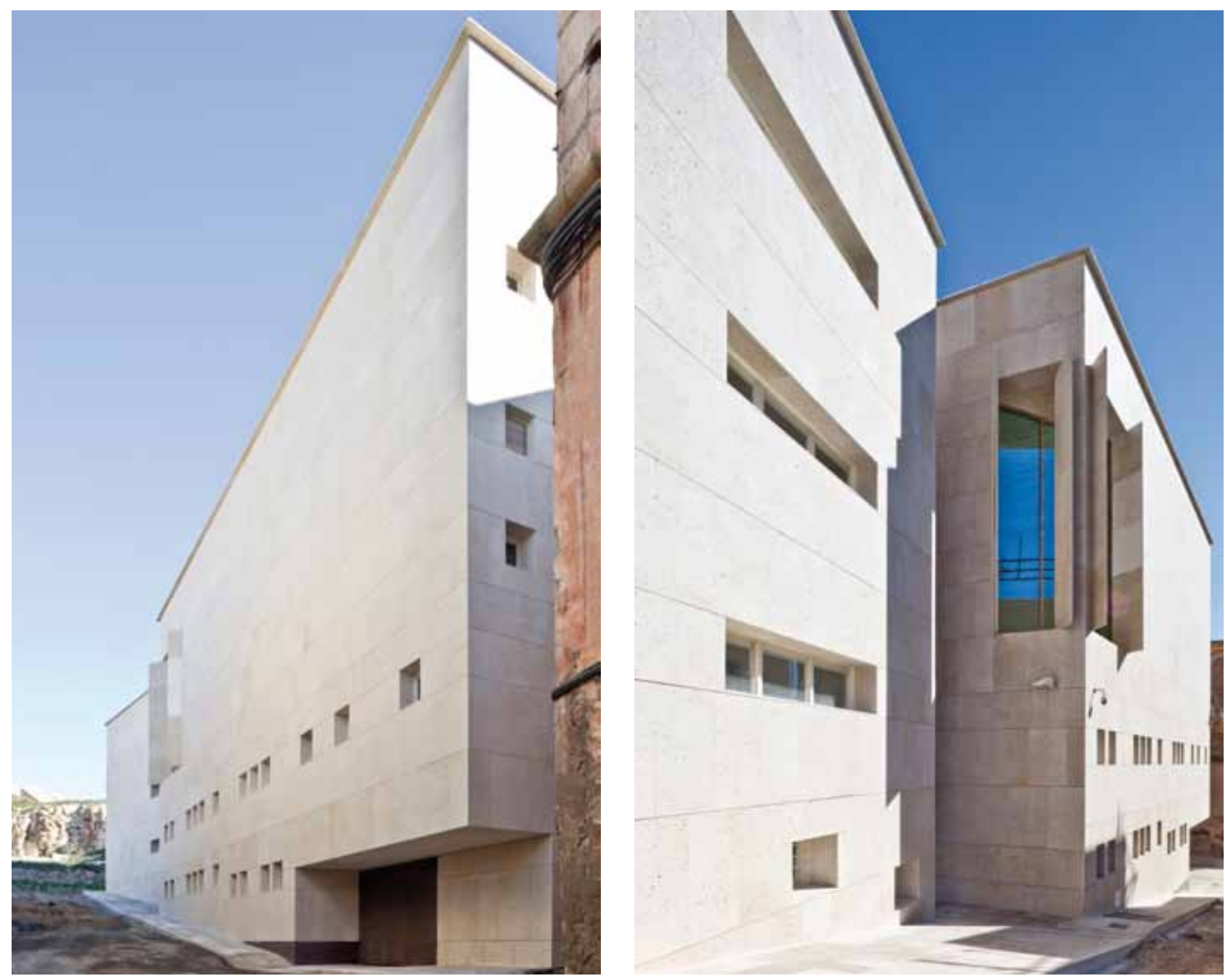

Fachadas calle Juez. Fotos: José Morón

La intervención ha pretendido constituirse en una pieza básica, en cuanto ejemplo y motor para la recuperación contemporánea, intentando reunir eficacia, sostenibilidad y respeto patrimonial para con las exigencias actuales y para con la herencia cultural de Almería y su entorno

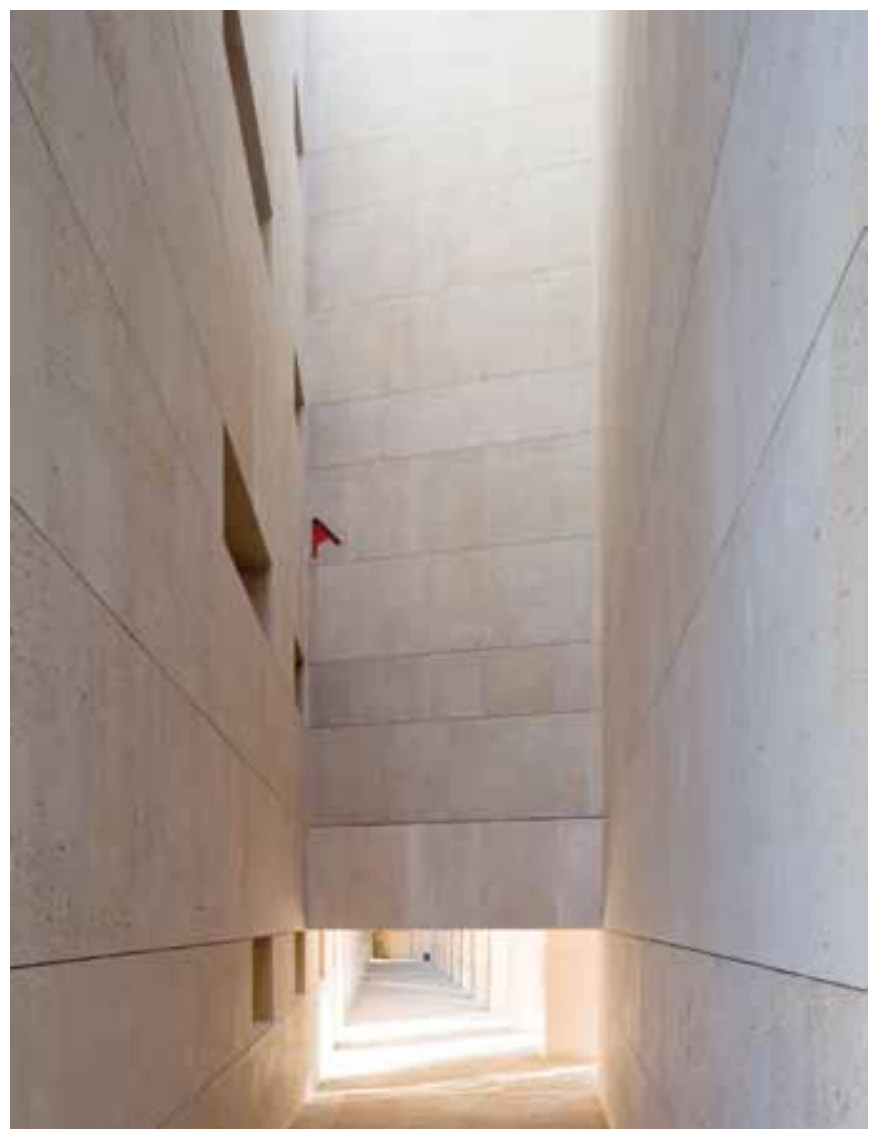

Adarve a la plaza desde calle Juez. Foto: José Morón 


\section{EL CONCURSO (2001)}

Era, por tanto, imprescindible la elaboración de un plan integral que, por una parte, considerara la máxima posibilidad de crecimiento en el propio entorno histórico de la antigua plaza, y, por otra, estableciera un orden funcional completo de la nueva administración municipal, fijando un marco genérico de traducción espacial a dicho ordenamiento y tomando decisiones sobre los servicios que fuera conveniente servir desde esta sede central y los que tuvieran que ser ubicados fuera de ella.

Las bases del concurso no contemplaban un programa pormenorizado, ni siquiera sectorial, de los futuros servicios municipales a contener. Lo cual permitió la consideración de la nueva sede como un complejo diverso de contenedores administrativos surgidos de una adecuada lectura de las preexistencias, una vez limpiadas y articuladas entre sí, de manera que se hiciese posible su funcionalidad conjunta y su continuidad distributiva y espacial como resultado de sus propios caracteres arquitectóni$\cos$, sin la violencia y arbitrariedad que con frecuencia encierran operaciones similares.

La propuesta premiada partía de una consideración equilibrada del conjunto a rehabilitar, sin identificar en él piezas singulares de particular interés, quizá con la relativa salvedad de la operación de galerias-fachada de la segunda mitad del XIX, según proyecto de Francisco Iribarne, de mayor ambición urbana que interés como arquitectura. Sí eran consideradas las dos casas, Yeó y Prats, insertas en el conjunto y ya maltratadas y maltrechas por un cúmulo de intervenciones y chapuzas, como las piezas de más interés del conjunto.

Por otra parte, la propuesta surgía de una manera particular de entender la arquitectura: considerarla como servicio, como conjunto de escuetas y económicas transformaciones tendentes a la resolución de los problemas, inadecuaciones e insuficiencias identificados. Cuestión, por otra parte, que quedaba muy abierta en las bases, como suele suceder. Sin pretensiones de dotar al conjunto de gestos espectaculares y llamativos o de ridiculas huellas de autoria.

Se confiaba en la recuperación de las tres galerias superpuestas entre si y adosadas o yuxtapuestas al conjunto anterior, como elemento clave que dotase al nuevo complejo de una espina dorsal completa que contuviese las circulaciones esenciales lineales, como el hilo de un collar de cuentas. De manera que la fachada decimonónica a la plaza principal y central se mantuviese y se pusiese en valor, mientras trasera y perimetralmente fueran apareciendo como episodios diversos, residuos y resultados de su compleja historia edilicia, los restos de casas antiguas.

La plaza, entendida como centro, corazón y pulmones del nuevo Ayuntamiento, fue también otra de las claves de la propuesta, que era crítica con la ramplona y destructiva situación a la que años de desidia e inconciencia la habian arrastrado, convirtiéndola en una desordenada compartimentación de cuatro calles paralelas a las cuatro fachadas, destruyendo su potencialidad espacial, urbana y representativa.

El concurso, con jurado formado, entre otros, por arquitectos de reconocido prestigio externos a la administración andaluza, fue gestionado desde la entonces Dirección General de Arquitectura y Vivienda de la Consejería de Obras Públicas de la Junta de Andalucía.

En los trámites de supervisión del primer proyecto básico, que, como el concurso, fue de todo el conjunto, la Delegación de Cultura de la misma Junta en Almería presentó su frontal oposición a cuestiones claves del proyecto, presentes ya en el concurso, que terminarian por obligar a la transformación notable del mismo.

- Así, se postuló el reconocimiento del actual edificio central como pieza a mantener en su integridad, incluida su escalera y el techo del antiguo salón de plenos, que se decía de ricas y exóticas maderas americanas, cuando descubrimos ser de escayola pintada de marrón, estando todavía en el ayuntamiento los moldes con los que se hicieron, todo ello, escalera incluida, en el más puro estilo de posguerra.

- De manera que la nueva escalera propuesta, que enlazaba el antiguo vestíbulo que, ampliado, se mantenía, con el nuevo salón de plenos, hubo de ser eliminada del proyecto, desvirtuándose el sentido principal de acceso.

- Igualmente se rompió el sistema general de circulaciones en paralelo a las fachadas de la plaza, así como la accesibilidad de la Alcaldia desde las distintas zonas funcionales.

- Debido a la supuesta competencia con la "cúpula" que corona el cuerpo del reloj, se obligó a la eliminación de los dos cuerpos que sobresalian de los planos de azotea que, en la propuesta, enlazaban con soluciones tradicionales y todavia frecuentes en la arquitectura doméstica de la casa almeriense, $y$, además, eran configuraciones que reforzaban la presencia visible del nuevo Ayuntamiento en un tejido urbano laberíntico.

- A pesar de ser evidentes muy recientes talas de palmeras y ficus en el arbolado de la plaza, que son los elementos claves de su partición en cuatro calles, se obligó al mantenimiento estricto de los restantes, haciendo inviable la ordenación nueva que la propuesta pretendia, acorde con su entendimiento como gran espacio urbano centrado, expresivo del Ayuntamiento que se extiende a su alrededor y compatible con la amable estancia como salón y con su esporádico uso como lugar de espectáculos públicos.

Todo ello ha hecho de la gestión de los sucesivos proyectos y modificados exigidos y de su ejecución en obra, un desconcertante y difícil ejercicio de supervivencia proyectual y agónica e incierta 


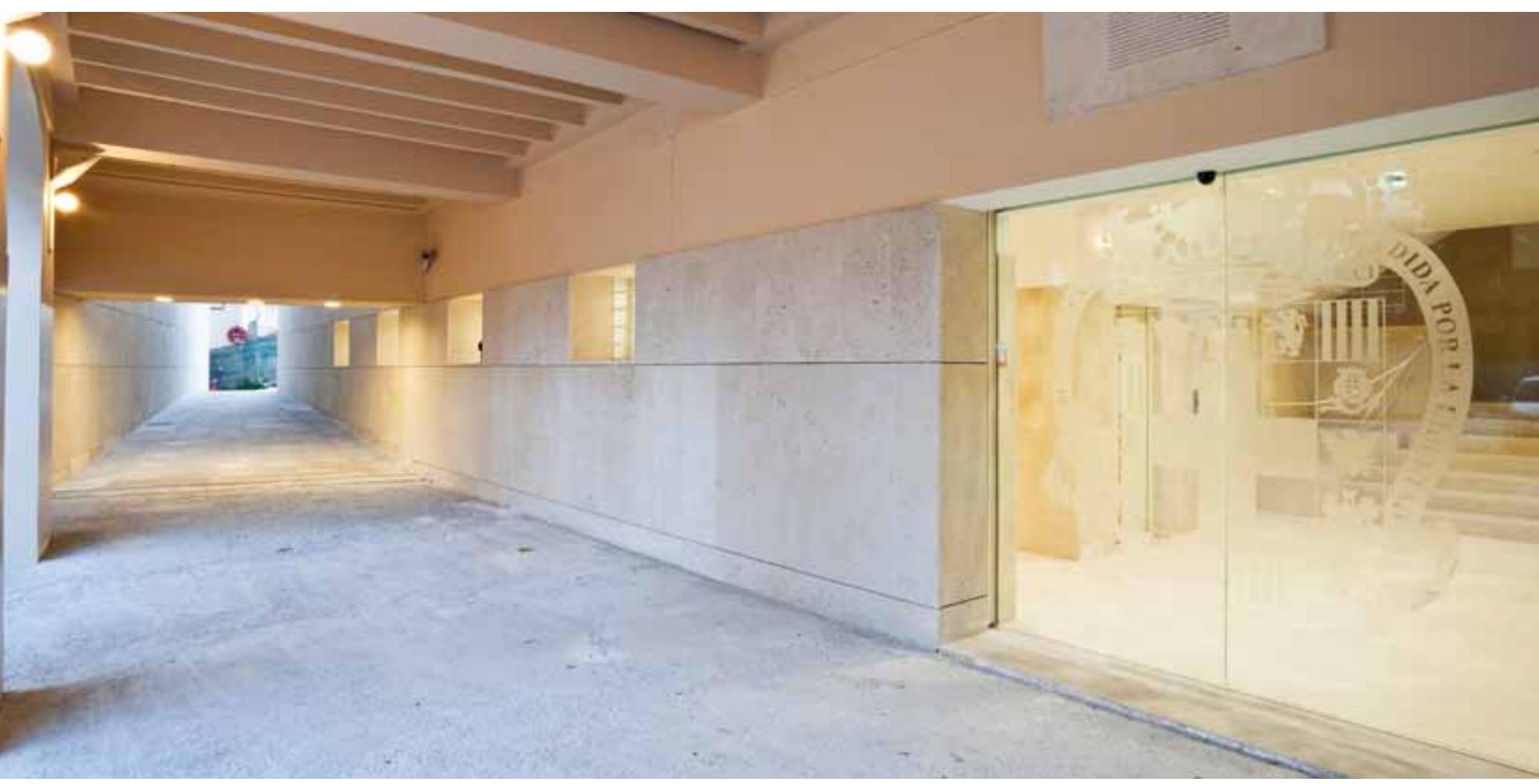

Galería de la plaza de la Constitución. Foto: José Morón

transferencia arquitectónica, que pone de manifiesto la extrema dificultad de gestión de un proyecto de esta envergadura y complejidad, en el que interviene, a lo largo de su enrevesada trayectoria, una amplia colección de instancias diversas, con diversos intereses, puntos de vista e intenciones. En este caso, se llegó a cuestionar la capacitación del jurado designado y la idoneidad de la propuesta seleccionada. ¿De qué sirve el más ilustre de los jurados (quizá nacional, quizá internacional) y su correspondiente concurso de máximas garantías, ante el ilimitado poder de cualquiera de los numerosos y obligatorios peajes por los que será cribado y a cuyos responsables, quizá, no se invitó al citado jurado, pero a los que asiste todo su derecho y obligación de opinar e imponer su particular criterio y discernimiento? Incluso un proyecto que pudo haber nacido discreto y con todas las bendiciones aparecerá como una pobre criatura abandonada a las fieras, los peligros del tiempo y del camino, los cazadores furtivos, los francotiradores, los enemigos declarados y los no presentidos... No sé si algún proyecto ha crecido y mejorado asi (mal)tratado y utilizado como arma arrojadiza de otras batallas quizá ajenas y distintas.

\section{DOS FASES}

Después de la elaboración de un proyecto básico unitario, con el que se dio inicios al continuado ejercicio de acoso y derribo, por

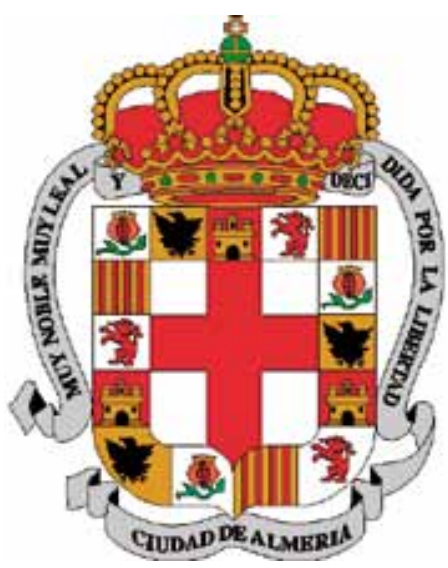

Escudo de Almería. Fuente: Ayuntamiento de Almería, Área de Protocolo

razones de dimensión, complejidad y, sobre todo, de ocupaciones, por parte del Ayuntamiento y otras instituciones, de distintas zonas afectadas, se decidió dividir la intervención en dos fases. La primera comprendia los edificios 5, 6, 7, 8 y 9 y la plaza de la Constitución.

La superficie total de suelo afectada por la intervención alcanza los $7.426 \mathrm{~m}^{2}$. La primera fase, cuya ejecución ahora culmina, tiene una extensión de $1.547 \mathrm{~m}^{2}$ de suelo, en los que se han edificado $7.367 \mathrm{~m}^{2}$ construidos y $389 \mathrm{~m}^{2}$ de espacio público. 

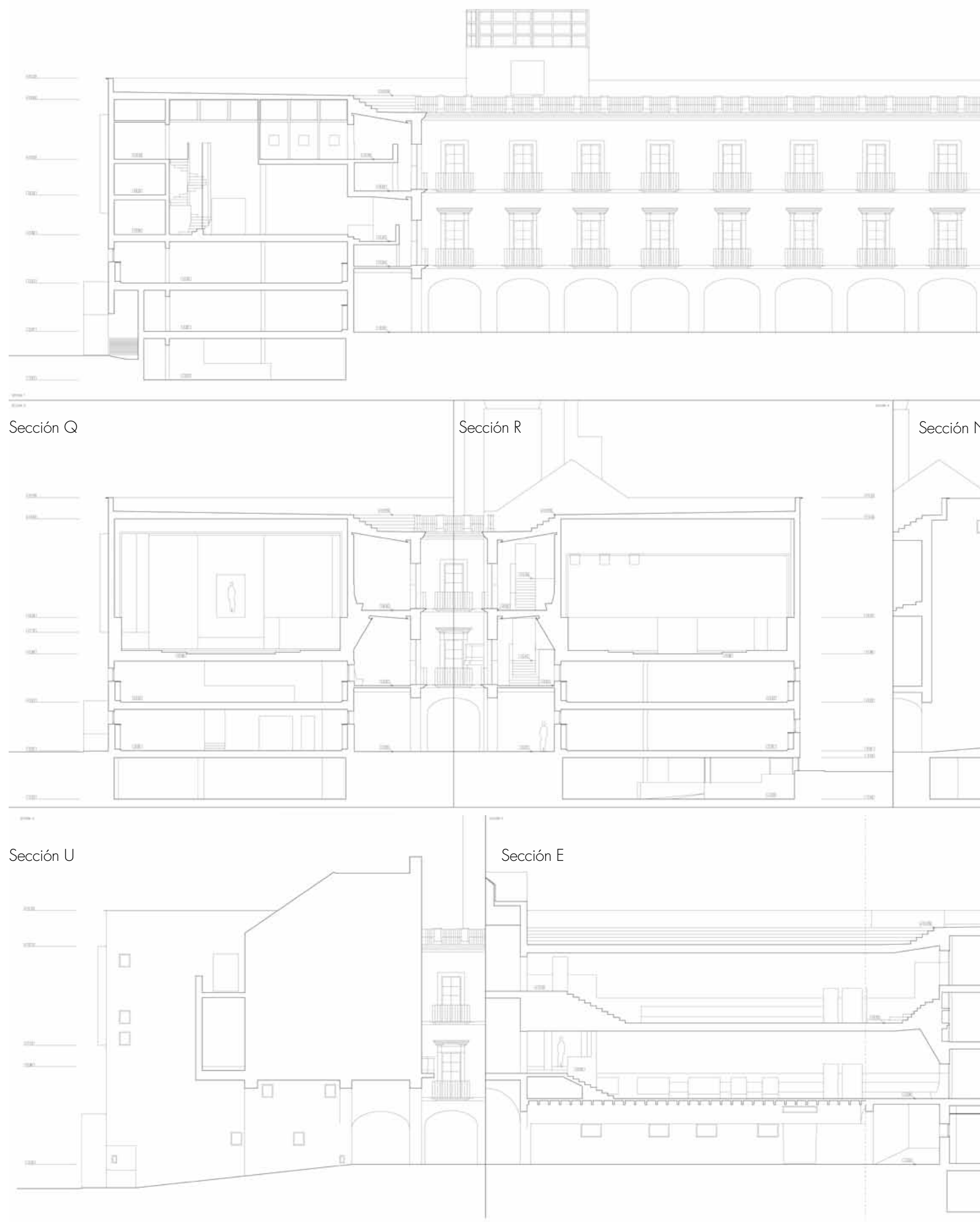
Sección $\bigcirc$

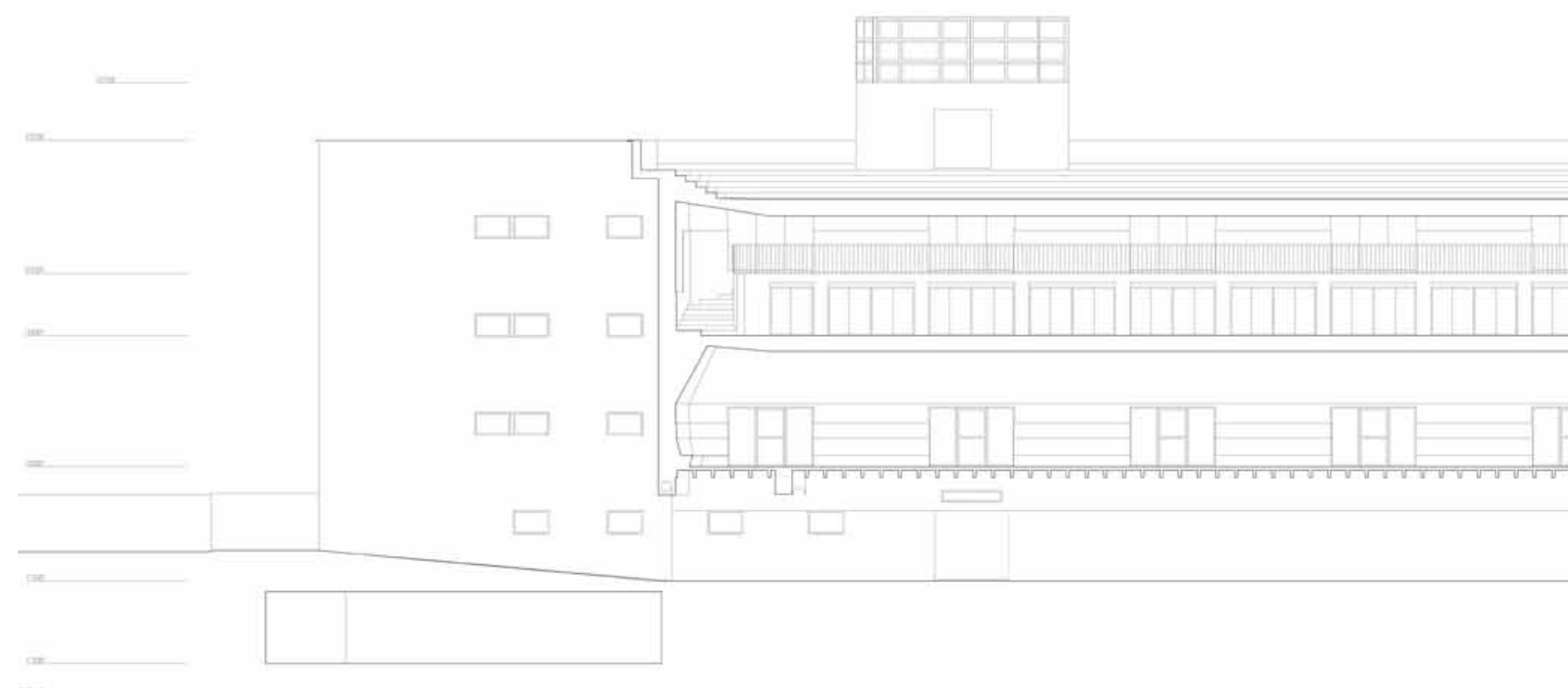

Sección L

ㅍ.

Sección B

Sección K

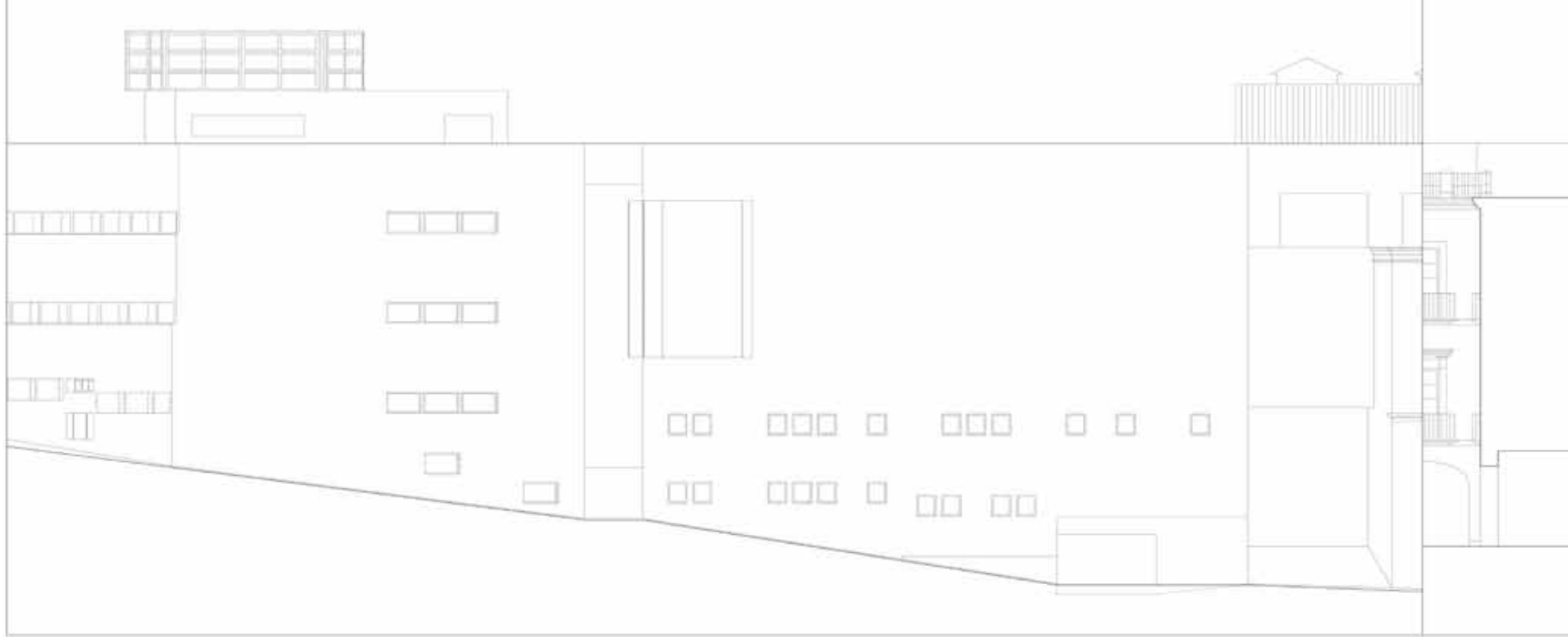






Planta cubierta

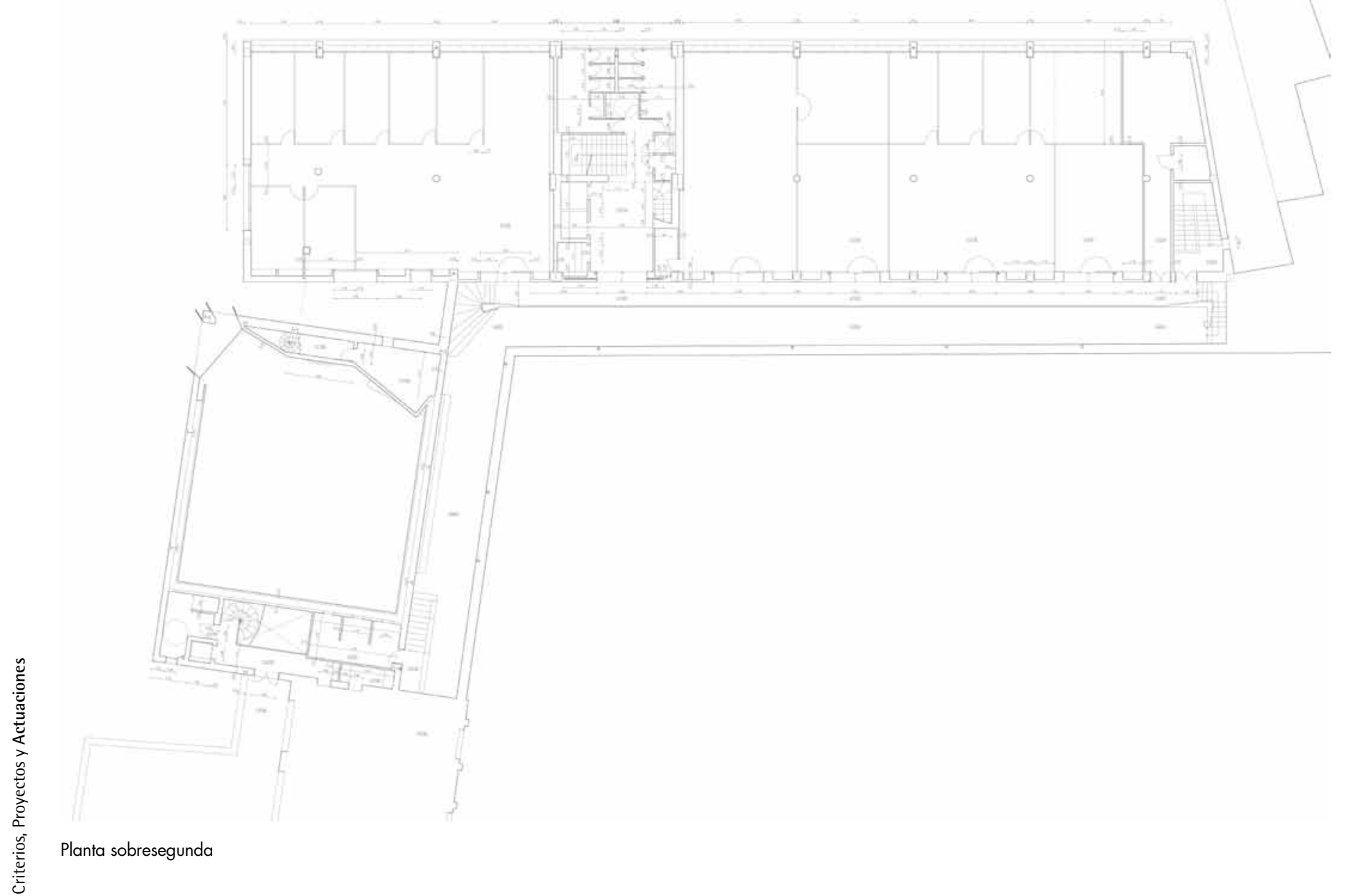

122 • Revista ph •Instituto Andaluz del Patrimonio Histórico • n 75 • agosto 2010 • pp. 108-131 


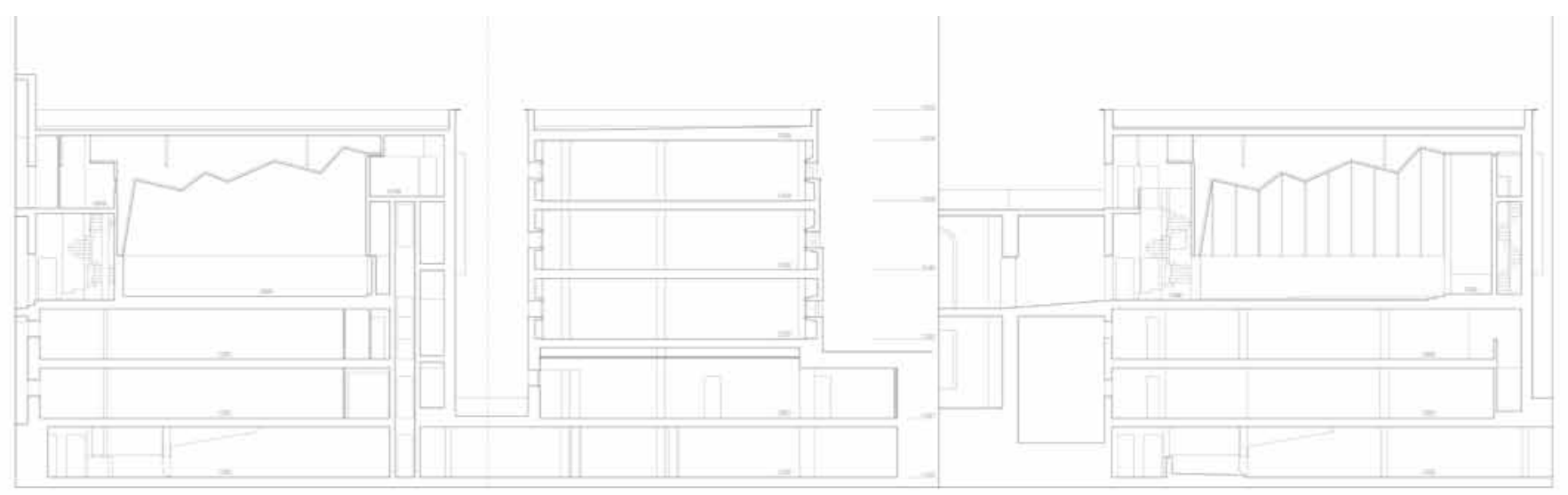

Sección D

Sección C

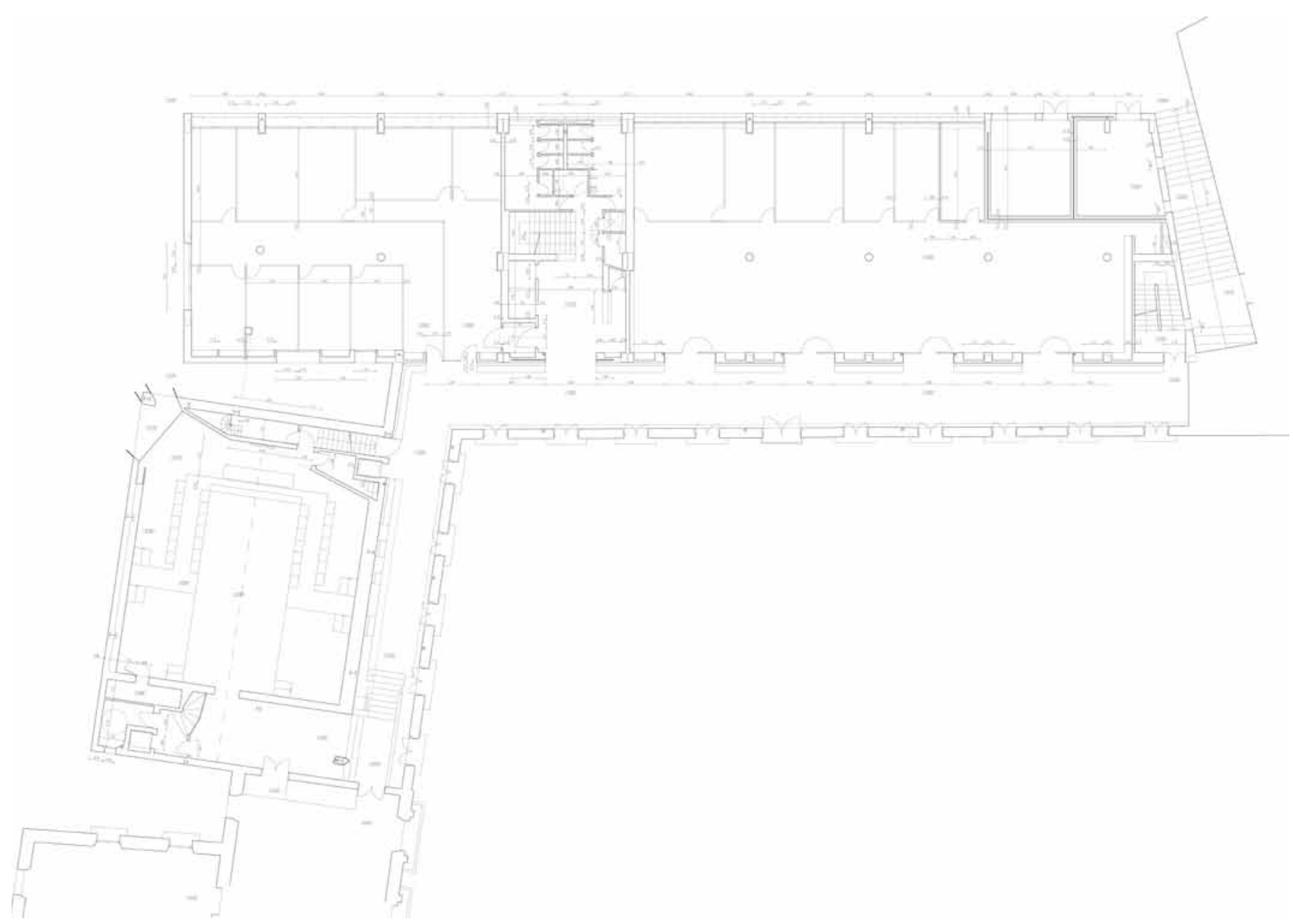

Planta primera 


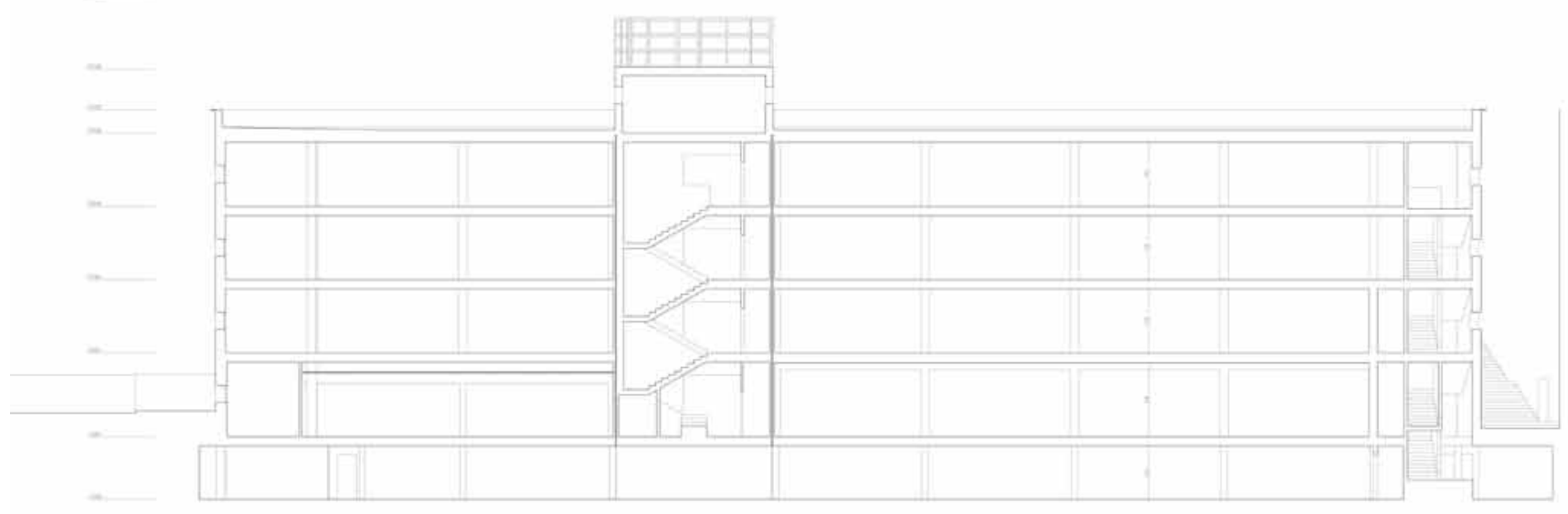

Sección $M$

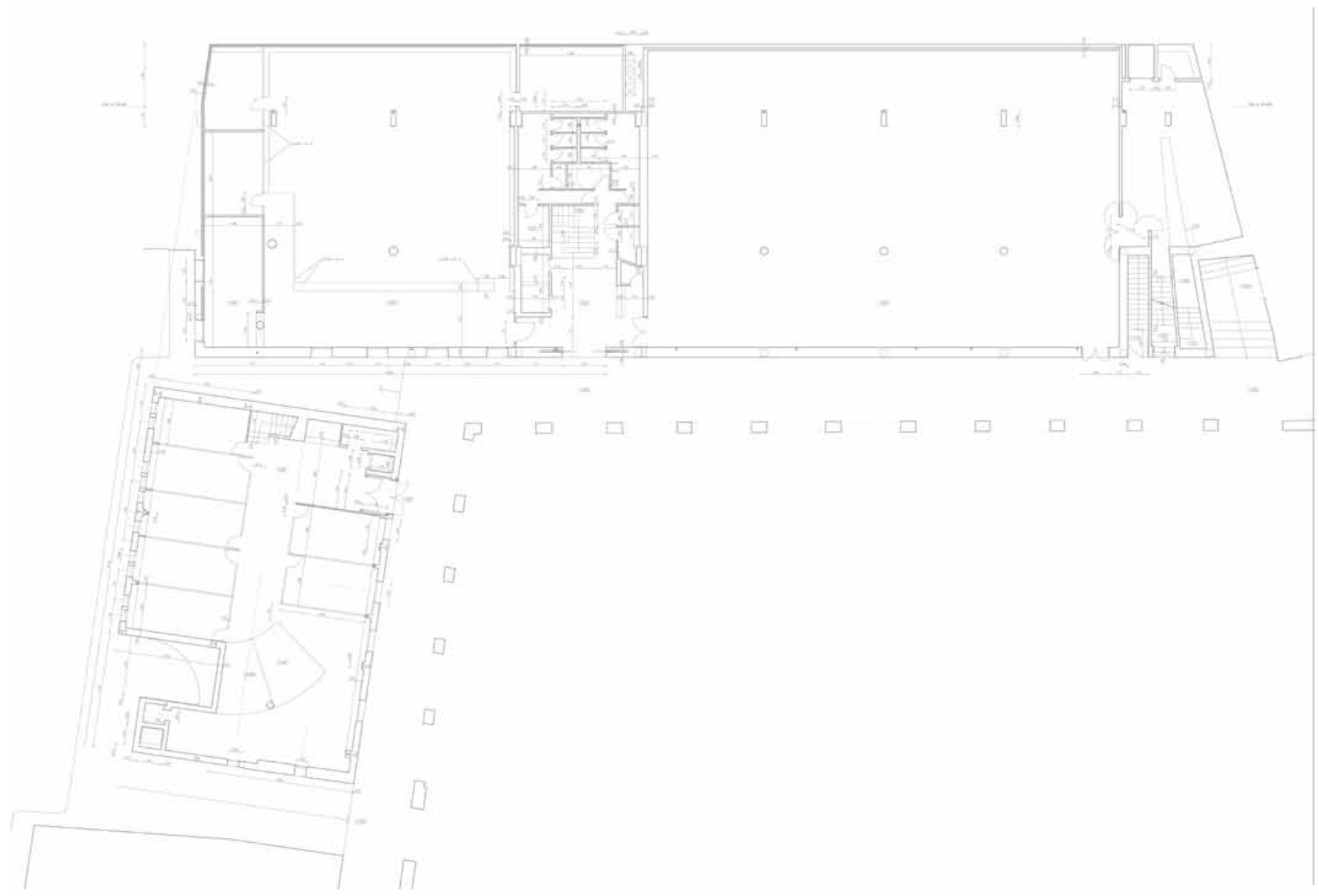

Planta baja

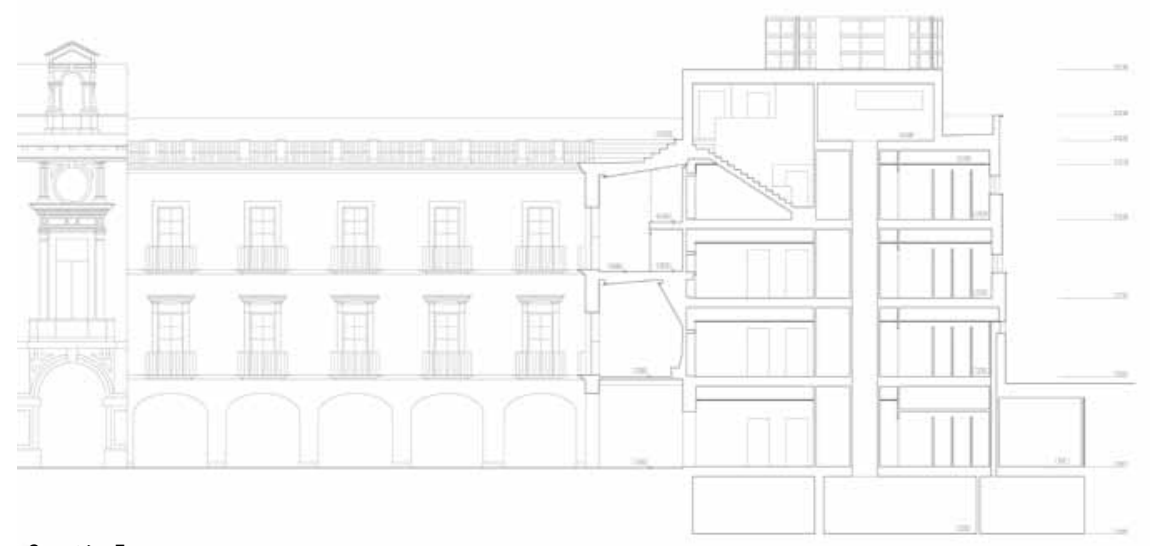

Sección F 


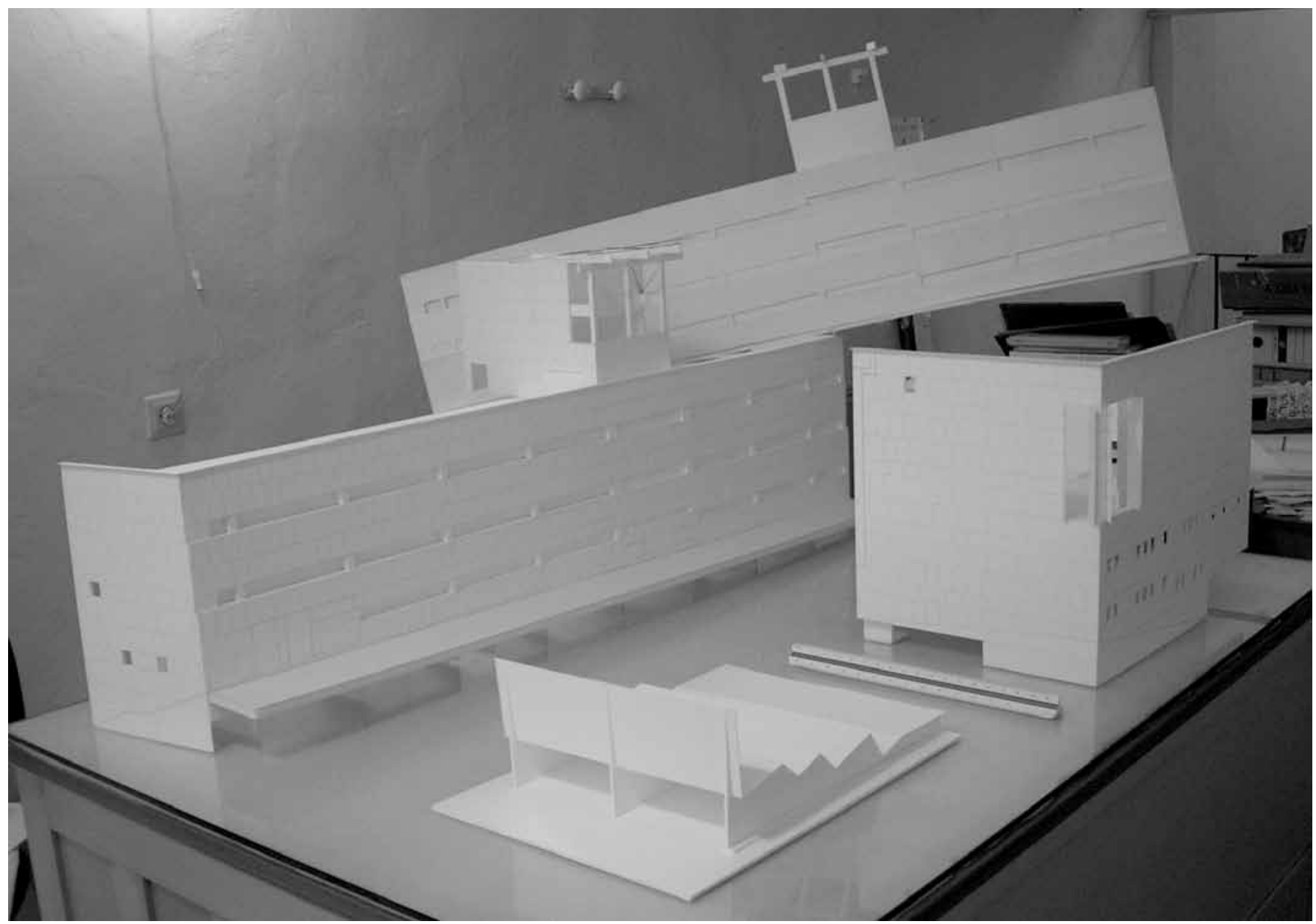

Maquetas de trabajo. Foto: Estudio J. R. Sierra

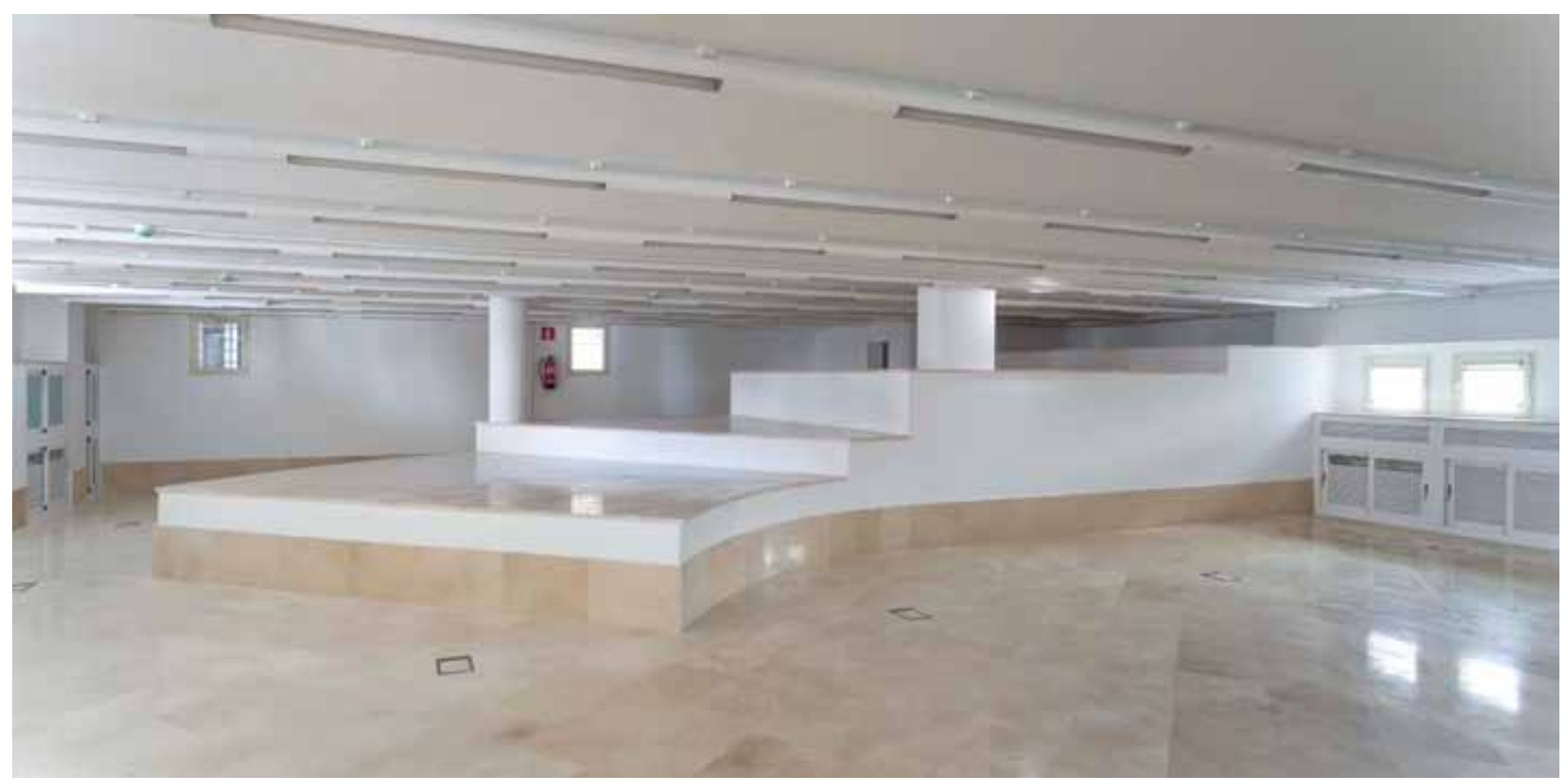

Interior de oficinas. Planta baja. Foto: Estudio J. R. Sierra 


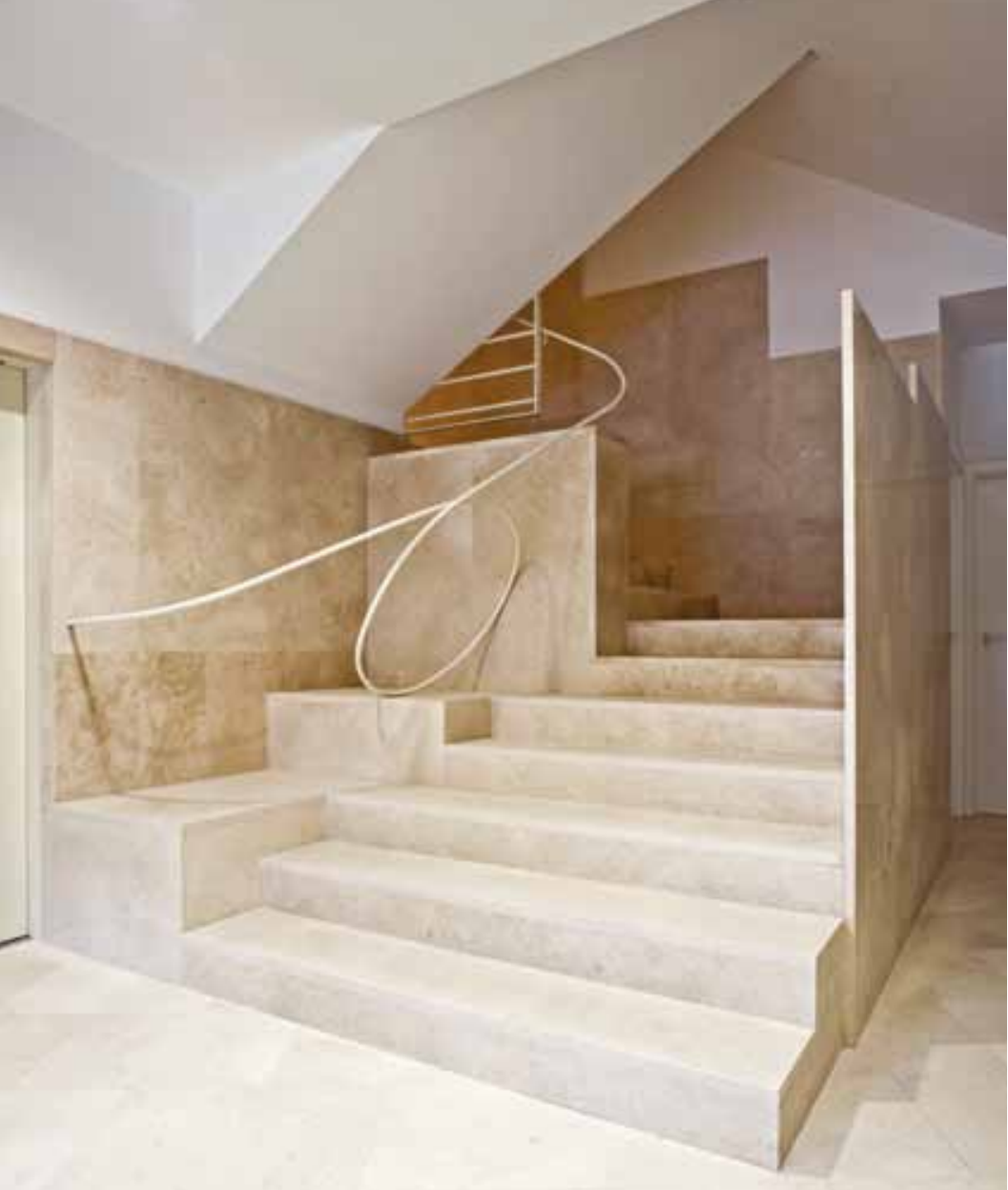

\section{LA INTERVENCIÓN}

Se trata de la transformación del grupo de edificios del Ayuntamiento, todos ellos alrededor de la plaza de la Constitución, de Almeria, cuya integración en la ciudad contemporánea constituye un requisito imprescindible para garantizar un destino equilibrado y eficaz al conjunto de la Almería futura, resultado de relaciones históricas muy diversas entre restos patrimoniales valiosos pertenecientes en general a la arquitectura doméstica como motor y ejemplo de otras iniciativas necesarias.

La intervención ha pretendido un conjunto de objetivos, en los que se compatibilizan los fines meramente funcionales y administrativos como futura sede de las oficinas municipales, con los correspondientes de carácter simbólico que deben atender a suministrar una imagen que aúne identidad formal y dignidad arquitectónica a uno de los edificios más representativos de la ciudad, si no su mayor representante. Por último, la intervención ha pretendido constituirse en una pieza básica, en cuanto ejemplo y motor para la recuperación contemporánea, intentando reunir eficacia, sostenibilidad y respeto patrimonial para con las exigencias actuales y para con la herencia cultural de Almeria y su entorno, que a su vez, por el sitio concreto donde se ubica el edificio, implica valores paisajísticos de máxima importancia, fundamentalmente en relación con la Alcazaba y con el cerro de San Cristóbal, cuya reurbanización, ahora en marcha, será la otra pieza clave para garantizar la recalificación histórica que este impor- tante sector urbano necesita. Es en este contexto donde debieran ser valorados con cuidado los episodios de configuración urbana ahora surgidos en el entorno, evidenciando la condición de borde de la nueva fachada del Ayuntamiento a calle Pósito, y sus relaciones con la llegada a sus pies de la ladera de la colina pelada. Un sitio que, por otra parte, puede llegar a ser clave en el uso de este sector urbano, en cuanto el papel que puede desempeñar en los sistemas de acceso a los focos de mayor interés cultural y turistico de la ciudad de Almería.

Se trata de una intervención compleja como resultado de la suma de muy diferentes operaciones que han atendido a las diversidades cronológica, constructiva, funcional y de mantenimiento de los diferentes edificios que componen el conjunto rehabilitado, todo ello de conformidad con las directrices y necesidades programáticas planteadas en las bases del concurso, así como en las sucesivas reuniones mantenidas con las administraciones implicadas.

Las más significativas de tales operaciones correspondientes a la fase 1 han sido las siguientes:

\section{Demoliciones}

La demolición de las edificaciones alineadas a calle Pósito, la mayoría de ellas restos de antiguas demoliciones y desplomes así como del edificio con fachada al tramo norte de la calle Juez, 
entre la plaza de la Alhóndiga Vieja y la calle José M. ${ }^{a}$ de Acosta. De esta manera se suministra un tratamiento unitario, de máxima rentabilidad funcional, a lo que obviamente es la pieza clave en el suministro de superficies diáfanas de oficinas capaces de resolver con su flexibilidad un programa funcional cambiante, como sin duda lo será el de las oficinas municipales.

\section{Rehabilitaciones}

La rehabilitación de los edificios antiguos más significativos del conjunto, actores principales en la, por otra parte, débil configuración de una imagen pública del conjunto municipal almeriense. Se trata, básicamente, de la galería de tres plantas y una crujía que fue añadida en el siglo XIX al conjunto doméstico para dar unidad formal y escala urbana a su fachada a la plaza. El sentido genérico de tal reforma ha consistido en la recuperación del carácter unitario interior, incorporando a los usos funcionales del Ayuntamiento la capacidad distributiva, de paseo y descanso que tal corredor posibilita.

La rehabilitación del conjunto de fachadas, tanto verticales como horizontales, techos de soportales, de la Plaza de la Constitución, conformadoras de la operación de unificación formal de dicha plaza, poniendo en valor los paños lisos de mortero en los que se delinean escuetamente las guarniciones pétreas de los balcones y los arcos carpaneles de planta baja.

\section{Sustituciones}

Las edificaciones de nueva planta que sustituyen a las zonas demolidas antes citadas y que conforman dos sectores bien diferenciados aunque unidos entre sí en sótanos y en fachadas-galerias a la plaza. Uno es el edificio conformado como pieza longitudinal de fachada alargada a calle Pósito, mientras su otro lado largo se adosa al sector correspondiente de galería a la plaza de la Constitución. El otro es la pieza que sustituye al antiguo edificio con fachada más larga a calle Juez e igualmente adosado a su sector de galería del XIX y que acoge el nuevo salón de plenos.

La configuración de la nueva cubierta, concebida como zona practicable y resuelta con los mismos materiales con los que se revisten suelos y fachadas de otras zonas accesibles, con la intención de que su uso desde el interior del Ayuntamiento, como zona de recepción y encuentros desde la que disfrutar vistas magníficas de la ciudad y su entorno, y su percepción desde zonas adyacentes exteriores, la configure como un factor esencial en el papel que el nuevo Ayuntamiento debe asumir como motor y ejemplo de revitalización del sector urbano donde se ubica.

\section{FICHA TÉCNICA}

\section{Promotores}

Junta de Andalucia. Consejeria de Vivienda y Ordenación del Territorio Ayuntamiento de Almería

Proyecto cofinanciado con fondo FEDER

\section{Gestión de la promoción}

Empresa Pública de Suelo de Andalucía

\section{Proyecto y dirección técnica de la obra}

José Ramón Sierra Delgado

Arquitecto

Gonzalo Cátedra Cátedra

Luis Calvo Hernando

Arquitectos técnicos

\section{Colaboradores de estudio}

Carlos Cañas, Luis Carbonell Eguaras, Miguel Ángel Gimeno, Aurelio Gómez-Bastero Martín, Joaquín Hurtado Gutiérrez, Fernando Llanes Muro, Pedro Muñoz Sánchez, Guillermo Carrillo Ayala y Carlos Rodriguez Campos

\section{Empresas colaboradoras \\ EDARTEC, estructuras \\ ETINSA, instalaciones}

\section{Empresa constructora}

ALDESA

José Antonio Valencia Alejandre

Arquitecto técnico (jefe de grupo de edificación)

Emilio Gómez Espigares

Ingeniero de caminos (jefe de obra)

\section{Superficie construida \\ $7.426 \mathrm{~m}^{2}$}

\section{Presupuesto total}

5.272.002,79 euros

Costo por $\mathrm{m}^{2}$ construido: 709,94 euros

\section{Fecha del proyecto}

noviembre 2003

\section{Inicio de obras de 1.a fase}

Septiembre 2006

Finalización de obras de $1 .^{\text {a }}$ fase

Febrero 2008 







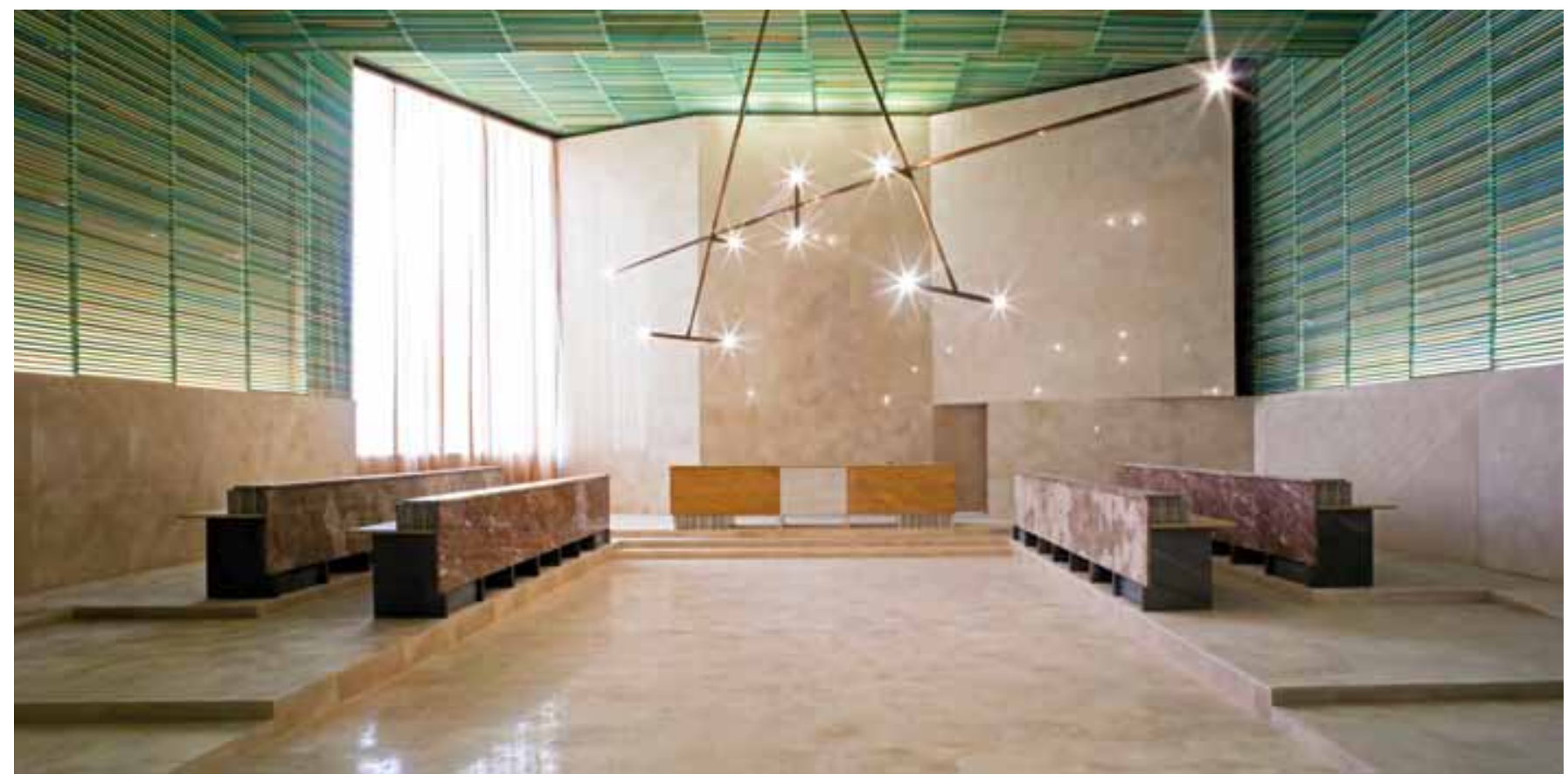

Salón de plenos. Foto: José Morón

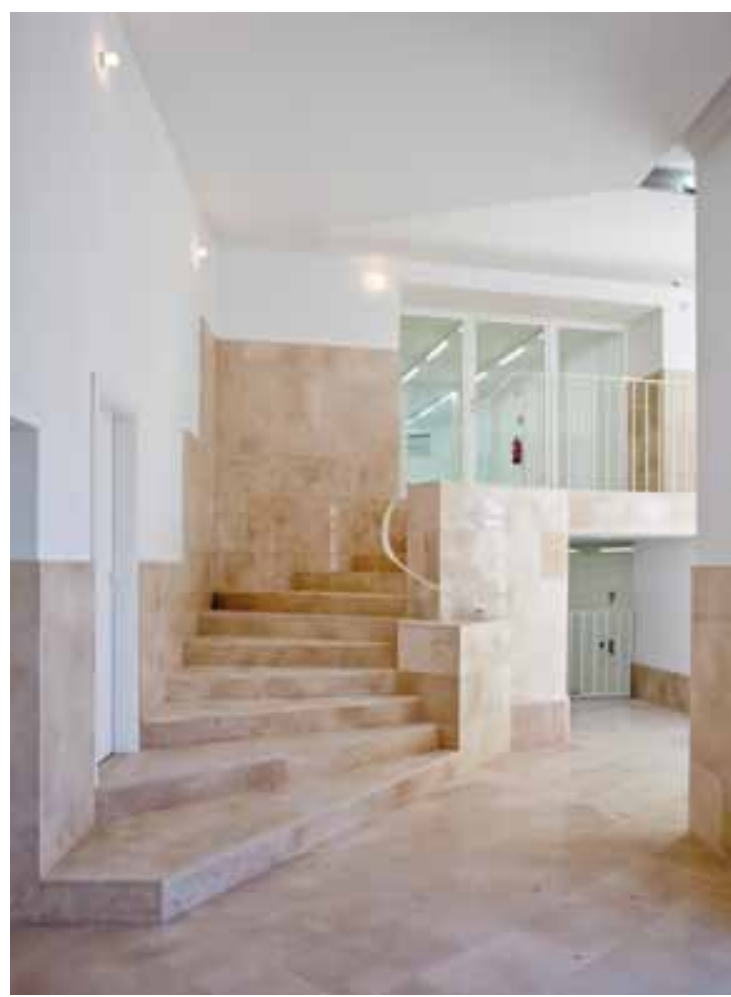

Galería planta sobreprimera. Foto: José Morón

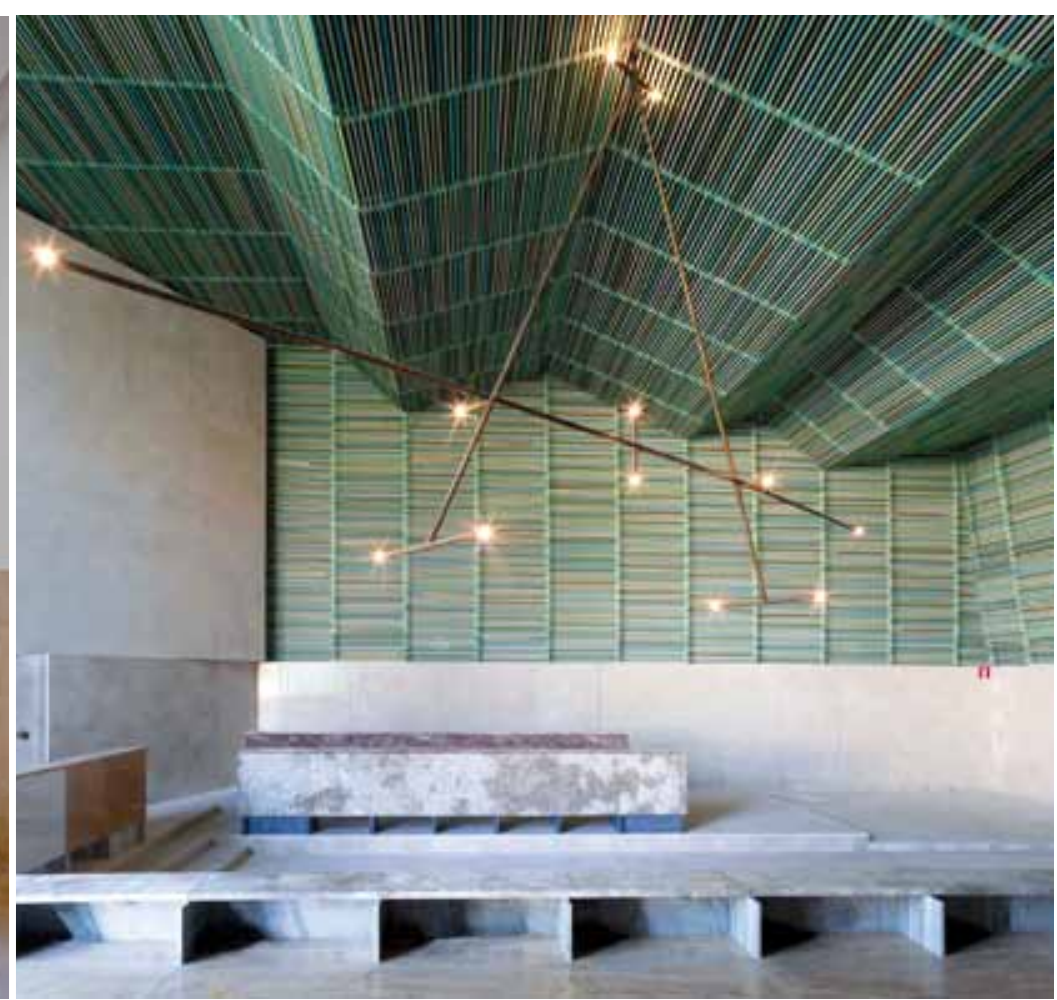

Salón de plenos. Foto: Estudio J. R. Sierra 


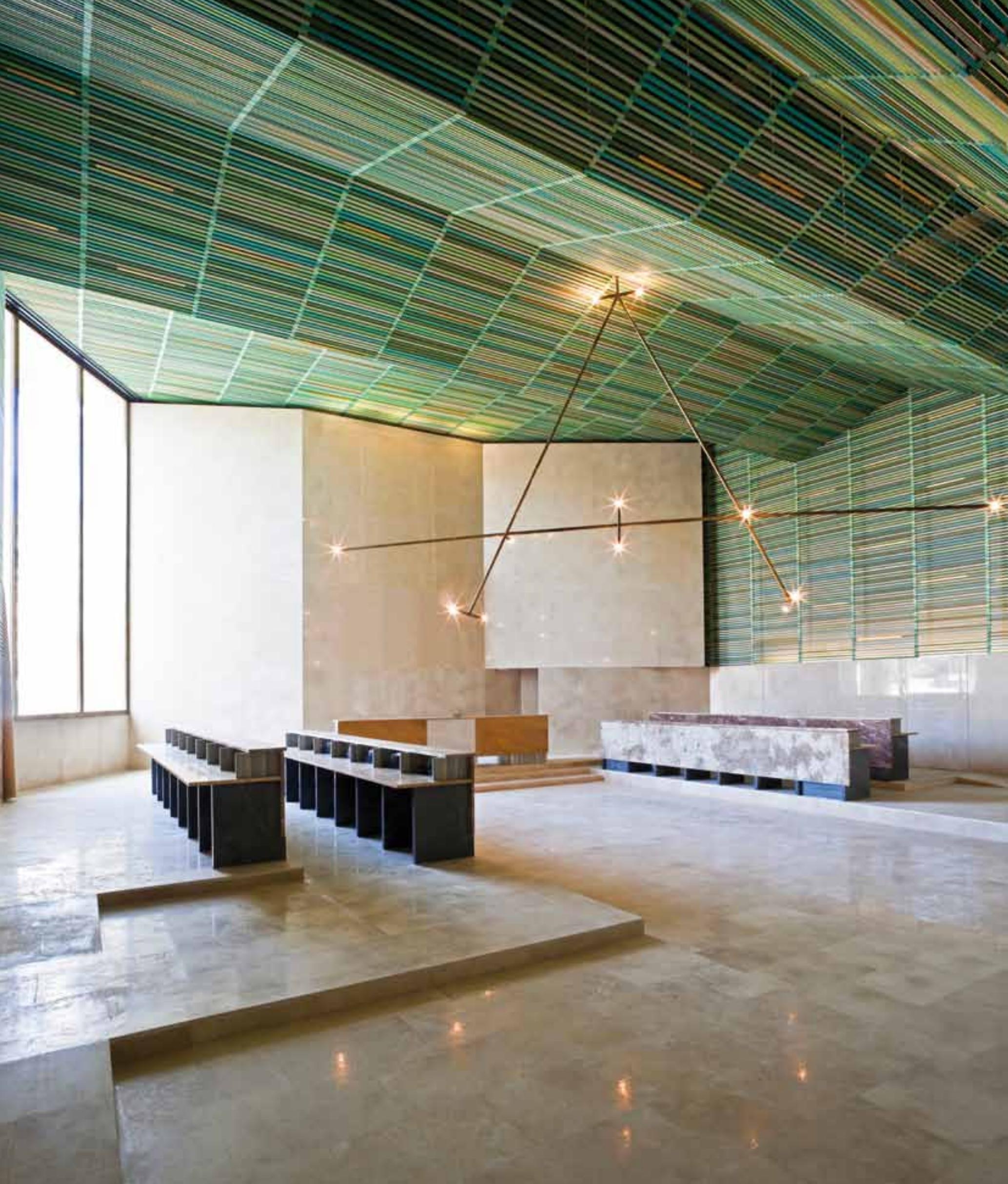

Salón de plenos. Foto: José Morón 


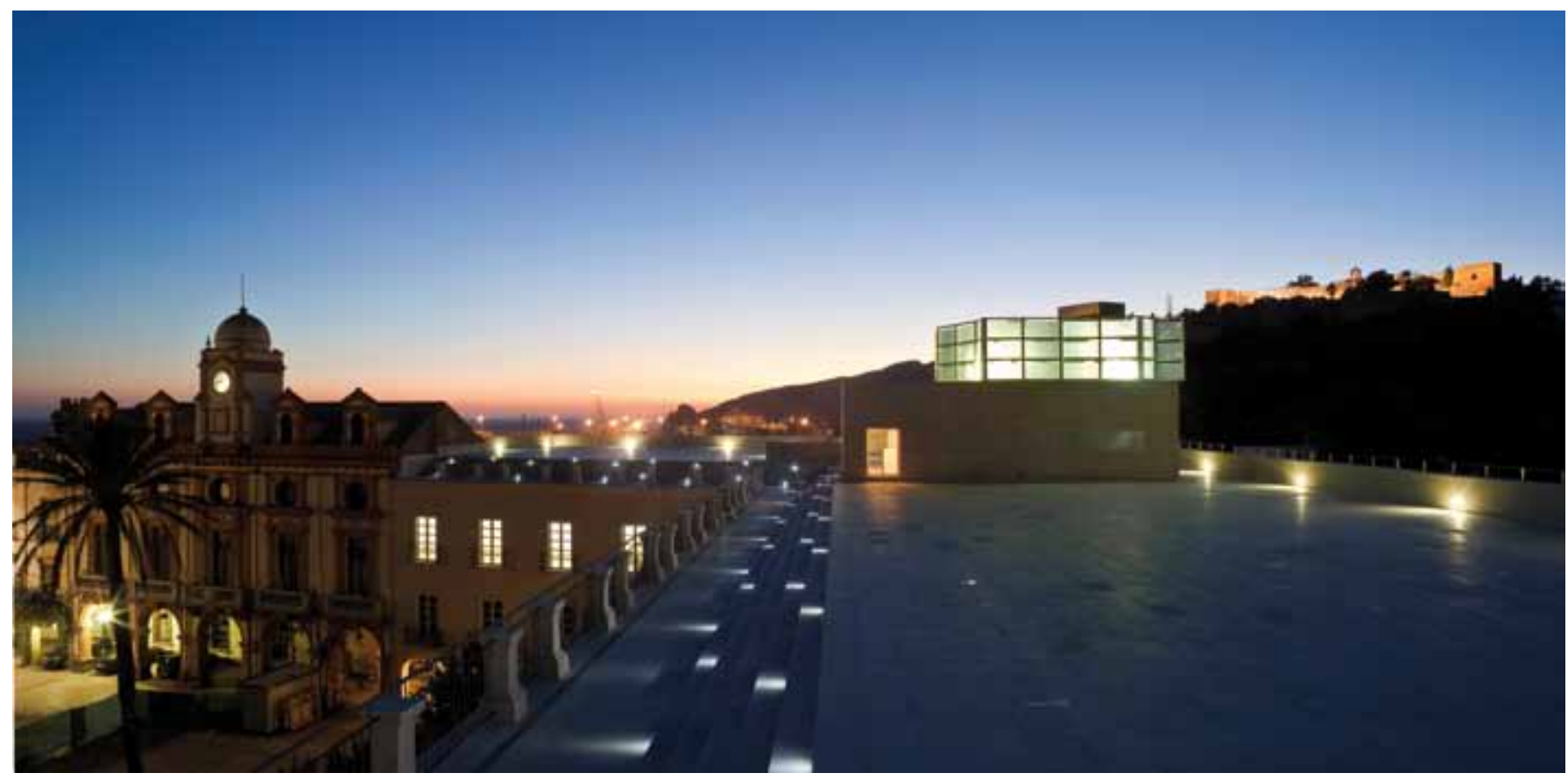

Noche y luz. Foto: José Morón

\section{UN EDIFICIO PÚBLICO}

\section{Luis Burillo}

Arquitecto, miembro del jurado del concurso

Ha pasado cierto tiempo desde que se celebró el concurso de las Casas Consistoriales de Almeria. Hoy podemos ver el resultado y comprobar que apoyar el trabajo de Sierra mereció la pena. Una voz solitaria y única la de este arquitecto andaluz.

Con los años (muchos años) y mi experiencia profesional he llegado a la conclusión de que la buena arquitectura emana, fundamentalmente, del mundo del arte. Si, del mundo del arte y no de otros ahora tan en boga: técnica, ciencia, etc. Decir esto y en estos tiempos puede parecer un anacronismo absoluto. Pero yo me reafirmo e insisto: si algo he echado de menos a lo largo de mi práctica profesional es no haber podido disponer de una mayor formación artística. Explico a los profanos en la materia que, desgraciadamente, los arquitectos españoles nos hemos formado en el "politecnicismo" (invento napoleónico importado en el siglo XIX), frente a los arquitectos de otros países cuyos estudios son más de "Facultad de Arte" y no tanto de "Escuela Técnica".

J. R. Sierra, en cambio, viene del interior del mundo del arte (fue un artista precoz, según dicen los libros y antologías de pintura) y eso ha marcado completamente su obra: su lenguaje arquitectónico es singular, diferente, alejado de todo estereotipo banal. Alejado también del lenguaje de la mayor parte de la arquitectura actual, reducido a un gigantesco y recurrente "collage" de sobadas imágenes y manidos clichés modernistas.

La pregunta elemental que uno se hace a continuación es: ¿verdaderamente la arquitectura ha de ser una obra de arte?. 0 más concretamente y en el caso que nos ocupa: ¿el edificio del Ayuntamiento de Almería necesita una intervención como la de Sierra?. Sí, rotundamente sí.

Imaginación, imaginar: el diccionario también define esta palabra como "idear". La arquitectura como obra de arte, en la obra pública me refiero, ha sido imprescindible para casi todas las sociedades avanzadas de la historia. Ahora, quizás, el arte de idear e imaginar (pero con rigor y autenticidad, no ese pseudo-arte que nos suelen ofrecer como verdadero) lo echamos de menos más que nunca.

"Arquitectura versus Arte": tema dificil y oscuro que se presta a mil equívocos y malas interpretaciones. Quizás no sea, aquí y ahora, el mejor momento para extendernos hablando de esta cosas. Sin embargo, uno no puede aproximarse, críticamente, a la obra arquitectónica de J. R. Sierra sin evitar pasar, auque sea en volandas, sobre temas tan procelosos. Voy a intentar salir del asunto sin explicarlo o desarrollarlo, simplemente invitando a la reflexión planteando una paradoja que a mí me parece bastante explicativa (es de mi invención y la he bautizado humoristicamente como "Paradoja de Burillo"). Permitanme que la plantee. Dice asi:

"Es un lugar común en la historia del arte, que en el siglo $V$ de la era anterior -conocido como el siglo de Pericles- los hombres fueron tan listos e iluminados (Sócrates, Platón, etc.) que pudieron construir ese prodigio de belleza y perfección que es el Partenón. Sin embargo, sucedió al revés. Los hombres pudieron llegar a pensar todo lo que pensaron gracias a que fueron inspirados (motivados, estructurados, construidos...) por ese conjunto de maravillosas molduraciones, prodigiosos relieves y exquisitas proporciones que constituyen el templo dórico".

J. R. Sierra: construir la mirada, pensar con las manos. 